\title{
Vertical PRODUCT DifFERENTIATION WHEN QUALITY IS UNOBSERVABLE TO BUYERS
}

\author{
GERHARD O. OROSEL \\ KLAUS G. ZAUNER \\ CESIFO WORKING PAPER NO. 1271 \\ CATEgory 1: Public FinAnCE \\ SEPTEMBER 2004
}

Presented at CESifo AREa Conference on INDUSTRIAL ORganisation MARCH 2003

\footnotetext{
An electronic version of the paper may be downloaded

- from the SSRN website: http://SSRN.com/abstract $=601345$

- from the CESifo website: www.CESifo.de
} 


\title{
VERTICAL PRODUCT DifFERENTIATION WHEN QUALITY IS UNOBSERVABLE TO BUYERS
}

\begin{abstract}
We analyze vertical product differentiation in a model where a good's quality is unobservable to buyers before purchase, a continuum of quality levels is technologically feasible, and minimum quality is supplied under competitive conditions. After purchase the true quality of the good is revealed with positive probability. To provide firms with incentives to actually deliver promised quality, prices must exceed marginal cost. We derive sufficient conditions for these incentive constraints to determine equilibrium prices, and show that under certain conditions only one or both of the extreme levels of quality, minimum and maximum quality, are available in the market.
\end{abstract}

JEL classification: D82, L11, L15.

Keywords: experience goods, product differentiation, product quality, asymmetric information.

Gerhard O. Orosel

Department of Economics

University of Vienna

Hohenstaufengasse 9

A-1010 Vienna

Austria

gerhard.orosel@univie.ac.at
Klaus G. Zauner

Department of Economics

University of York

Heslington

York YO10 5 DD

United Kingdom

kgz1@york.ac.uk 


\section{Introduction}

We consider a market for an experience good ${ }^{1}$ and analyze in particular which quality levelsout of a continuum of technologically feasible levels - are offered in equilibrium. Our results can explain the casual observation that in many markets for experience goods quality is generally low, and high quality is either impossible to find or extremely expensive. Particular examples of such markets, besides others, can be found among markets for agricultural produce and food products. For instance, the markets for many vegetables and fruits are divided into two quality segments, "ordinary" and organic. Organic products are supposedly free of pesticides - and expensive. In contrast, ordinary products usually are produced with significant amounts of pesticides and are relatively cheap. Firms do not offer, for intermediate prices, agricultural products that have been produced with modest amounts of pesticides. Moreover, consumers cannot observe the amount of pesticides used in the production of a particular product or the contamination level, respectively. However, specific checks and tests by capable agencies can reveal this information. Accordingly, we assume, in our model, that consumers cannot observe the true quality of the respective product even after consumption, but that after purchase the true quality of the good will become publicly known with positive probability. $^{2}$

The lack of high quality products in a particular market may simply be the consequence of customer preferences. Customers may just not be willing to pay the higher production cost associated with better quality. In such a case complaints about the lack of high quality are irrelevant from the point of view of market performance. However, we provide a plausible

\footnotetext{
${ }^{1}$ In our model experience goods are goods where (a) buyers cannot observe the quality of a particular product before deciding whether or not to buy, (b) buyers detect with positive probability the quality of the respective product after purchase, and (c) contracts cannot be conditioned on quality. This definition differs slightly from the usual definition in that even after purchase quality is detected only with positive probability and not necessarily with certainty. It includes goods where a customer's own experience will never reveal the true quality, but checks by certain agencies will, e.g., tests by health authorities for hazardous substances contained in a given product. The notion of experience goods has been introduced (together with the complementary notion of inspection goods) by Nelson (1970).

${ }^{2}$ Unobservable quality is frequently associated with a product's genetic, organic, and chemical properties but may also relate to the respective production processes (e.g., as regards child labor, environmental implications or animal welfare). Although consumers cannot detect these attributes by their own experience, tests by public agencies or consumer organizations can find out. Since in any given period only few goods are tested, for a producer such tests are random events, and we will take account of this in our model.
} 
model where some or even all customers are perfectly willing to pay the higher production cost (but not necessarily the higher price) associated with better quality. Nevertheless, under certain conditions at most two different levels of quality are offered in equilibrium - one of them being the lowest and the other one the highest among the technologically feasible levels. Moreover, if high quality is available at all, then for a price that is high relative to production cost.

In this study we combine two strains of literature, (i) the incentive approach to experience goods (pioneered by Klein and Leffler 1981, and followed up by Shapiro 1983, and others ${ }^{3}$ ), and (ii) the analysis of Bertrand equilibria in markets with vertical product differentiation (see, e.g., Gabszewicz and Thisse 1979, 1980, and Shaked and Sutton 1982, 1983). ${ }^{4}$ The fact that due to incentive or signalling reasons experience goods must have high prices relative to cost, has a significant effect on the equilibrium outcome. For example, for the duopoly case Bester (1998) has shown that if in a standard Hotelling model of spatial competition the horizontally differentiated good is an experience rather than an inspection good, the equilibrium outcome may be "minimum differentiation" rather than "maximum differentiation."

A related, but different approach deals with informational product differentiation as a barrier to entry (see, e.g., Schmalensee 1982, Bagwell 1990). In these models customers' informational differences with respect to different brands may constitute a barrier to entry. The informational differences are in fact differences with respect to supplier reputation. Whereas the incumbent has reputation (the quality of his product is "known"), a new entrant has no reputation (the quality of her product is not "known"). In contrast to this literature, we abstract from reputation as much as possible. ${ }^{5}$ Specifically, we assume that customers trust firms whenever conditional on this trust a firm has no incentive to "cheat," i.e., to

\footnotetext{
${ }^{3}$ See, e.g., Bagwell and Riordan 1991, Bester 1998, Riordan 1986, Rogerson 1988, Wolinsky 1983, among others.

${ }^{4}$ For a Cournot analysis of vertical product differentiation see, e.g., Gal-Or (1983). Gabszewicz and Grilo (1992) analyze the Bertrand equilibrium of a vertically differentiated duopoly where consumers have exogenous beliefs about which of the two firms sells high quality and which sells low quality. Another strain of literature, based on Mussa and Rosen (1978), deals with quality provision by a monopolist (see, e.g., Gabszewicz and Wauthy 2002 and the references therein). However, due to differences in focus the conclusions of this literature are not readily comparable to our results.

${ }^{5}$ Nevertheless, reputation plays an important role in our model as well, as it is necessarily the case in any model of an experience good market. However, in our model the role of reputation is more implicit. In particular, we do not focus on how reputation is gained and lost and how it can be used strategically.
} 
provide lower quality than announced. This assumption captures a minimal requirement for firms' reputation. It only strengthens our conclusions, if it is more difficult to acquire reputation. Thus, our results do not depend on a good answer to the difficult question of how to gain and how to lose reputation. ${ }^{6}$

The rest of the paper is organized as follows. First, we present the model in Section 2. Then, in Section 3, we derive the incentive compatibility constraints for firms to provide high quality. In Section 4, we show that due to these incentive compatibility constraints only low quality may be available in the market even though preferences for high quality may be "strong" relative to production costs of high quality. In Section 5, we demonstrate that under certain conditions equilibrium prices are determined by incentive compatibility constraints, whereas customer preferences and the distribution of customer types only determine the quantities demanded, given equilibrium prices. In Section 6, we analyze the case where customers' willingness to pay for quality is convex with respect to quality, and in Section 7 the case where it is concave. Finally, we conclude in Section 8. All mathematical proofs are relegated to the Appendix.

\section{The Model}

We consider a market for an experience good that is homogeneous except for quality. That is, in our model there is (potentially) vertical product differentiation but no horizontal product differentiation. Time is measured in discrete periods $t \in\{1,2, \ldots\}$. There is a pool of $N \geq 2$ ( $N$ possibly infinite) firms that are capable to produce each quality $v \in[0,1]$ of a given (experience) good at constant marginal cost $c(v)>0$, where the function $c:[0,1] \rightarrow \mathbb{R}_{++}$is strictly increasing. That is, marginal cost is independent of quantity but increasing with respect to quality. Moreover, since $c(v)$ is strictly increasing, quality can be

\footnotetext{
${ }^{6}$ Basically, for our conclusions we only need to assume that there is some way to gain reputation and that a firm will lose its reputation, if it provides lower quality than promised. These assumptions are innocent. If it is impossible to acquire the reputation of being a high quality producer, all products in the market will be of low quality, and no additional analysis is needed. If it is impossible to lose reputation, the respective firm will always provide low quality, and therefore among rational customers it will be impossible ever to acquire the reputation of being a high quality producer. Of course, the details of how exactly a firm's reputation is influenced when it provides lower quality than promised, matter for the details of the firm's incentive compatibility constraint. However, our results depend on the existence, not on the details of that incentive compatibility constraint.
} 
measured without loss of generality in such a way that cost is linear in quality, i.e.,

$$
c(v)=c(0)+\gamma v,
$$

where $\gamma$ is some positive constant. ${ }^{7}$ Put differently, we use unit cost to measure quality. In addition to the $N$ firms that are capable to produce each of the technologically feasible quality levels, there are infinitely many firms that are capable of producing minimum quality $v=0$ at cost $c(0)$. Although a firm may be capable of producing many quality levels, we assume that in each period it can produce and offer only one particular level of quality of the respective product.

In equilibrium not all firms will be active in the market and produce. Firms that are active in the market are distinguished between "brand names" and "no names." No names produce only minimum quality $v=0$, whereas brand names may produce any quality level $v \in[0,1]$. Even if a no name is capable of producing positive quality, it will not do so because customers believe that all no names provide only minimum quality (Assumption 3 below). A brand name has to announce publicly the quality of its product in each period and we call this the "announced quality." Actual quality is private information of the firm and may or may not coincide with the announced quality. Between periods brand names can change their announced and actual quality levels, respectively. We assume that no names have no entry cost, whereas each brand name has to incur a positive entry cost $\eta>0$, identical for all firms, in order to establish the respective brand together with an associated distribution channel. A brand name that voluntarily leaves the market may enter again, either simultaneously or later, but it has to pay the entry cost for each entry. Since no names have no entry cost, in any equilibrium minimum quality is offered under perfectly competitive conditions and the respective price is $c(0)$ in every period. All no names have zero payoff. Brand names choose their respective prices, together with their respective quality levels, simultaneously at the beginning of each period. That is, we assume Bertrand competition.

In each period there is an atomless continuum of customers of (Lebesgue) measure 1. Customers' total expenditures are non-negative and uniformly bounded in every period.

\footnotetext{
${ }^{7}$ Let $V \in\left[V_{\min }, V_{\max }\right]$ be any measure of quality with associated marginal cost $C(V)>0$ that increases in $V$ but is constant in quantity. Defining $v \equiv\left[C(V)-C\left(V_{\min }\right)\right] /\left[C\left(V_{\max }\right)-C\left(V_{\min }\right)\right] \in[0,1]$ gives the required normalized measurement of quality. For any quality level $\hat{V}$ with normalized equivalent $\hat{v}$ we get the marginal cost $c(\hat{v})=C(\hat{V})=C\left(V_{\min }\right)+\left[C\left(V_{\max }\right)-C\left(V_{\min }\right)\right] \hat{v}=c(0)+\gamma \hat{v}$, where $\gamma \equiv$ $C\left(V_{\max }\right)-C\left(V_{\min }\right)$.
} 
Customers live one period and are distinguished by "types" $s \in S=\left[s_{\min }, s_{\max }\right] \subset \mathbb{R}$ according to their willingness to pay for quality. We assume that the cumulative distribution function of $s$, denoted by $F(s)$, has a density $f(s)$. Customers' preferences are specified by the following assumption.

Assumption 1 (Customer Preferences). Each customer buys at most one unit of the experience good. The payoff from not buying the experience good is normalized to zero. For customers of type $s \in S$ the payoff from buying one unit of the experience good of quality $v$ for the price $p$ is given by $U(v, p, s)=R(v, s)-p$. For all $v \in(0,1]$ and $s \in S$, the function $R(\cdot, \cdot)$ is strictly increasing in quality $v$.

If quality were immediately observable to customers and firms had no entry cost, competition would drive the price for quality $v$, denoted by $p(v)$, down to marginal cost $c(v)$, provided $N$ is sufficiently "large." In the extreme case of no entry cost and a continuum of firms, each customer type $s \in S$ could find a firm that offers the level of quality that this type prefers most at prices $p(v)=c(v){ }^{8}$ In the particular situation where at prices $p(v)=c(v)$ all types prefer maximum quality $v=1$, all firms would offer the highest feasible quality for the price $c(1)$. However, we consider a good where neither buyers nor other firms can observe the quality of a particular product, and contracts cannot be conditioned on quality. In such a situation, a firm could save on cost by producing lower quality than announced, and in the following we refer to such behavior as "cheating."

There are many different aspects of quality. Some of these the customer can observe immediately (like whether a fruit is rotten), some she can detect after a relatively short period of use (like the mileage of a car), some she can discern only after a long time (like the durability of a good), and some she will never know with certainty (like some features of product reliability, such as the probability of a breakdown). Moreover, some aspects, like the content of certain hazardous elements in food or toys, can be detected by an appropriate monitoring agency but not by the ordinary customer herself. We model the customers' uncertainty about the quality of the respective good in a way that is consistent with the last case (but not restricted to it). Specifically, Assumption 2 below covers the case where in

${ }^{8}$ The most preferred quality is either a corner solution $(v=0$ or $v=1)$ or, assuming differentiability, satisfies the condition $\partial R(v, s) / \partial v=\gamma$, i.e., at an interior optimum the marginal willingness to pay for quality must equal the "marginal cost of quality." 
each period the true quality is revealed to the public with some probability $\varphi \in(0,1]$, and where with the complementary probability $1-\varphi$ there is no information about a product's quality.

In some cases, the information that a certain product does not have the announced quality may spread slowly and the firm which sells it in the market may be able to exploit the reputation it has acquired in the past for a relatively long period after it has started to cheat. In other cases, this information may become public almost instantaneously and force the firm to close down. For example, a watchdog agency may randomly test brand names' products, and if the test shows that the true quality is below the announced quality the respective firm may have to close down, e.g., because it loses its customers or is forced by a legal authority to exit the market. The relevant point is not how fast or to what extent the respective firm has to reduce its business, but that a cheating firm risks that it will be punished either by the public or by a legal authority. The expected punishment gives rise to an incentive compatibility constraint that, if satisfied, induces the firm to provide the announced quality. Independent of the details of the model, this constraint necessarily implies that the price of a good above minimum quality must be sufficiently above its marginal cost. Otherwise the firm would cheat and produce only minimum quality. Since customers cannot immediately observe quality and contracts cannot be conditioned on quality, a firm that produces high quality must earn an informational rent. The threat of losing this rent if it cheats provides the incentive for the firm to actually produce the announced quality (Klein and Leffler 1981).

The previous discussion motivates the following assumption, which in particular captures the case where watchdog agencies perform random tests of the brand names' products with some probability $\varphi \in(0,1]$, and firms caught cheating have to exit the market and receive a payoff of zero from that moment onwards. ${ }^{9}, 10$

\footnotetext{
${ }^{9}$ The assumption that the payoff drops to zero is a simplification. For incentives a significant reduction of the payoff (to a still positive value) is sufficient. Empirically, such reductions can be observed. For example, Coyle (2002, pp. 29-30) points out (with respect to food quality): "A company involved in the spread of a foodborne pathogen can .... face costs imposed by courts or government agencies, including fines, product recalls, and temporary or permanent plant closures as well as large liability settlements and associated legal costs. Potential market and liability losses are strong incentives for food firms to ensure the food supply is as safe as possible."

${ }^{10}$ This implies that a firm that has to close down has no physical capital or other assets to sell. If the firm has some assets or a "scrap value," this would change the specific form of the incentive constraint below, but not the general argument. It would make a difference, though, if cheating firms could be forced to pay
} 
Assumption 2 (Quality Monitoring). If in any period $t \in\{1,2, \ldots\}$ the true quality of a product is below the quality announced by its producer, the respective brand name has to exit the market with positive probability $\varphi \in(0,1]$ and receives a payoff of zero from that moment onwards. ${ }^{11}$ With the complementary probability $1-\varphi$ providing lower than announced quality in any period $t \in\{1,2, \ldots\}$ has no effect for the respective brand name.

The assumption that the punishment for cheating is market exit need not be taken literally. The model covers all cases where brand names that cheat are punished in such a way that in expectation a cheating brand name loses $\varphi$ percent of its future payoff. For example, rather than having to leave the market with probability $\varphi$, a brand name that cheats may lose $\varphi$ percent of its customers for sure. Or it may lose $\varphi / \pi$ percent of its customers with probability $\pi \in(0,1)$.

This is not a paper on reputation. Rather, we want to characterize the equilibrium outcome when it is as easy as possible for firms to acquire reputation for being a high quality producer. Specifically, we assume that customers trust firms whenever conditional on this trust the respective firm has no incentive to cheat.

Assumption 3 (Customer Beliefs). Customers cannot observe the true quality of a brand name. They believe that the true quality is the announced quality, unless given these beliefs it is optimal for a firm to provide lower quality. Otherwise, they believe that the true quality is the minimum quality $v=0$. No names are believed always to provide minimum quality.

We assume that all firms have the same discount rate $\rho>0$. The associated discount factor is denoted by $\delta \equiv \frac{1}{1+\rho} \in(0,1)$. A firm's payoff is the discounted sum of its profits per period if it has entered the market, and zero otherwise. If more than one brand name offers the same quality $v \in[0,1]$ and there is a unique firm that is the cheapest one, it gets all the demand for this quality. If the cheapest brand name among those offering the same quality is not unique, all brand names that sell for the lowest price share the respective demand equally.

Since no names have no entry cost, they always offer quality $v=0$ for the price $p(0)=$ $c(0)$ under perfectly competitive conditions. Therefore, we restrict the terms "entry" and arbitrary large fines. However, for fines below a certain threshold the general argument remains valid.

${ }^{11}$ The respective firm may be allowed to enter as a no name. Recall that all no names have a payoff of zero. 
"incumbent" to brand names. Moreover, because no names do not behave strategically, we do not treat them explicitly as players in the game. In contrast, potential and actual brand names act strategically. In their decisions they take the "competitive fringe" of no names into account, as well as the strategies of the other players.

Our analysis is based on the following game. The set of players consists of brand names and customers. Brand names know the distribution of customer preferences, but cannot observe the individual types. The cost function (2.1) and the rest of the model are common knowledge. In each period $t \in\{1,2, \ldots\}$, the game proceeds in four stages. In the first stage, at the beginning of the period, brand names simultaneously decide whether to enter or, respectively, to exit the market. That is, brand names that have not yet entered the market decide whether to enter, and brand names that have entered in the past decide whether to exit. In the second stage, still at the beginning of the period, all brand names in the market observe the moves made in the first stage and choose simultaneously announced quality, actual quality, and price (each for the respective period). In the third stage, which takes place at the end of the period, customers decide whether and from which supplier to buy one unit of the good. These decisions are executed and the period's payoffs accrue. Finally, in stage four, each brand name that had provided some quality below the announced quality has to leave the market forever with probability $\varphi>0$. A brand name that has to leave the market receives no further payoff (but keeps the payoffs received so far).

Since we are not interested in collusion among firms, we want to rule out folk theorem type results. In standard models this can be done by considering only those equilibria of the dynamic game that consist of playing a particular equilibrium of the stage game in every period. In our model the situation is somewhat different because the only reason why firms do not cheat are their future rents, and therefore the game that incumbent firms play in each period is not the relevant "stage game." In any one-period "stage game" (as well as in any finite version of the dynamic game) incumbents would always cheat, and since customers would anticipate this and thus not buy the respective product, no brand name would enter the market and no positive quality would be available in equilibrium. In our model, the analogue of an equilibrium (in pure strategies) of the dynamic game that consists of playing an equilibrium of the stage game in every period, is what we call an equilibrium in stationary strategies or, for short, a stationary equilibrium. We define a brand name's strategy to be stationary, if it satisfies the following two conditions: (i) the firm either enters the market in 
the first period $t=1$ or not at all; (ii) if the firm had entered, its announced quality, actual quality, and price are constant in time and independent of the history of actions. Accordingly, an equilibrium (in pure strategies) is stationary, if all equilibrium strategies are stationary. It is the requirement that equilibrium strategies are independent of the history of actions that prevents collusion. In a stationary equilibrium, equilibrium strategies are not only constant along the equilibrium path but also at off-equilibrium nodes. However, this holds only for equilibrium strategies. Deviating strategies are not constrained to be stationary. ${ }^{12}$ With the important exception of Section 4, our equilibrium concept throughout the paper is the one of a stationary equilibrium in pure strategies. ${ }^{13}$ For the results of Section 4 collusion plays no role and therefore we consider all Nash equilibria in pure strategies.

\section{Incentive Compatibility Constraints}

In this section, we derive the incentive compatibility constraint (for short: incentive constraint) for a firm to provide a given quality $\bar{v} \in(0,1]$ in a stationary equilibrium. Consider a stationary equilibrium, where in some period $t$ a firm offers a product of some announced and actual quality $\bar{v} \in(0,1]$ for some price $\bar{p}$, sells $\bar{x}$ units in this period, and plans to do the same in every future period. For this strategy the sum of expected discounted profits is

$$
\delta \sum_{\tau=t}^{\infty} \delta^{\tau-t}[\bar{p}-c(\bar{v})] \bar{x}=\frac{\delta}{1-\delta}[\bar{p}-c(\bar{v})] \bar{x} .
$$

An alternative strategy is to cheat and provide only minimum quality for $K \geq 1$ periods (where $K$ may be infinite), risking involuntary exit; and to produce again quality $\bar{v}$ thereafter (if $K$ is finite), conditional on being still in the market. The associated sum of expected discounted profits is

$$
\begin{aligned}
& \delta \sum_{\tau=t}^{t+K-1} \delta^{\tau-t}(1-\varphi)^{\tau-t}[\bar{p}-c(0)] \bar{x}+(1-\varphi)^{K} \delta \sum_{\tau=t+K}^{\infty} \delta^{\tau-t}[\bar{p}-c(\bar{v})] \bar{x} \\
= & \delta \frac{1-\delta^{K}(1-\varphi)^{K}}{1-\delta(1-\varphi)}[\bar{p}-c(0)] \bar{x}+\delta^{K}(1-\varphi)^{K} \frac{\delta}{1-\delta}[\bar{p}-c(\bar{v})] \bar{x} .
\end{aligned}
$$

\footnotetext{
${ }^{12}$ Below, we show in Lemma 1 of Section 5 that for stationary equilibria it is nevertheless sufficient to consider stationary strategies.

${ }^{13}$ Since firms cannot observe each others' actual qualities, there are no proper subgames. Therefore, subgame perfection plays no role.
} 
Consequently, the resulting incentive constraint for the firm to actually provide quality $\bar{v}$ is

$$
\frac{\delta}{1-\delta}[\bar{p}-c(\bar{v})] \bar{x} \geq \delta \frac{1-\delta^{K}(1-\varphi)^{K}}{1-\delta(1-\varphi)}[\bar{p}-c(0)] \bar{x}+\delta^{K}(1-\varphi)^{K} \frac{\delta}{1-\delta}[\bar{p}-c(\bar{v})] \bar{x}
$$

Dividing by $\delta$ and rearranging gives

$$
\frac{1-\delta^{K}(1-\varphi)^{K}}{1-\delta}[\bar{p}-c(\bar{v})] \geq \frac{1-\delta^{K}(1-\varphi)^{K}}{1-\delta(1-\varphi)}[\bar{p}-c(0)]
$$

or $\bar{p} \geq c(\bar{v})+\frac{1-\delta}{\delta \varphi}[c(\bar{v})-c(0)]=c(\bar{v})+\frac{1-\delta}{\delta \varphi} \gamma \bar{v}$. Since $\frac{1-\delta}{\delta}=\rho$, we get

$$
\bar{p} \geq c(\bar{v})+\frac{\rho}{\varphi} \gamma \bar{v} .
$$

In a stationary equilibrium, this inequality has to hold for all quality levels $\bar{v} \in(0,1]$ that are actually produced. ${ }^{14}$ It cannot be that some quality $\bar{v}$ is sold at a lower price because at a lower price the respective firm would cheat and this would be anticipated by its customers.

Let $\hat{p}(v)$ denote the minimum price for quality $v \in[0,1]$ in a stationary equilibrium, i.e.,

$$
\hat{p}(v) \equiv c(v)+\frac{\rho}{\varphi} \gamma v, \quad v \in[0,1]
$$

These prices include the "incentive" or "informational" cost $\frac{\rho}{\varphi} \gamma v$ in addition to the production cost $c(v) \cdot{ }^{15}$ In any stationary equilibrium the price $p(v)$ must satisfy

$$
p(v) \geq \hat{p}(v)
$$

for each quality $v \in[0,1]$ that is sold in the market. ${ }^{16}$

\footnotetext{
${ }^{14}$ It is easy to check that the incentive constraint is identical, if a brand name that cheats loses for sure $\varphi$ percent of its customers at the end of each period it had cheated (rather than having to exit the market with probability $\varphi$ ).

${ }^{15}$ If the producer does not sell the product directly to customers but via dealers, the respective dealers may have an opportunity to cheat by selling a fake product instead of the real one. In this case, similar to the producer, a dealer must earn a rent in order not to cheat. Consequently, incentive costs accrue at the dealer stage as well. A dealer's incentive cost will show up as a higher markup on the cost price. If the distribution channel for the good consists of several stages, the cumulative incentive costs may be very high. In order to avoid too high a markup on the producer's price, the producer may establish her own network of stores or company outlets, although this would be inefficient if no incentive costs accrued in the distribution channel. In our model, we do not take such additional costs in selling the experience good into account. However, the presence of such costs is a reason to regard $\rho / \varphi$ as large.

${ }^{16}$ As Jean-Charles Rochet has pointed out to us, there is a related problem in the regulation of banks: deposit-rate ceilings can be used as incentives for banks to invest in safe rather than in inefficiently risky assets ("gambling assets") because deposit-rate ceilings increase banks' profits per period and thus their franchise (or charter) values (Hellmann et al. 2000, Repullo 2002).
} 


\section{Minimum Quality Only}

Although the incentive constraints (3.3) have been derived for stationary equilibria, this section shows that they have some relevance for all equilibria. We say that some given quality $v \in[0,1]$ is available in the market (for short: available) in some period $t$, if in period $t$ some firm produces this quality $v$ and offers its product at a price which at least some costumers are willing to pay, i.e., at a price that results in sales. Recall that by normalization every customer's payoff is zero when she does not buy the good at all, and that minimum quality $v=0$ is always offered for the price $p(0)=c(0)$. Assume that some given quality $\bar{v}>0$ is offered for some price $p(\bar{v}) \geq \hat{p}(\bar{v})$. If $R(\bar{v}, s)-\hat{p}(\bar{v})<\max [R(0, s)-c(0), 0]$ for all $s \in S$, customers will not buy quality $\bar{v}>0$ for the price $p(\bar{v})$. Each customer prefers either to buy minimum quality for the price $c(0)$ or not to buy at all. Consequently, quality $\bar{v}>0$ will not be available in a stationary equilibrium. If this holds for all positive levels of quality, i.e., if $R(v, s)-\hat{p}(v)<\max [R(0, s)-c(0), 0]$ for all $s \in S$ and all $v \in(0,1]$, then in any stationary equilibrium either only minimum quality is available or the good is not available at all. Proposition 1 generalizes this observation to all equilibria.

Proposition 1. If for no positive level of quality $v \in(0,1]$ customers are willing to pay the price $\hat{p}(v)$, i.e., if $R(v, s)-\hat{p}(v)<\max [R(0, s)-c(0), 0]$ for all $s \in S$ and all $v \in(0,1]$, then every Nash equilibrium in pure strategies has the property that positive quality is never available in the market. Depending on preferences, the respective good is either available only in minimum quality or, if $R(0, s)<c(0)$ for all $s \in S$, is not available at all.

Under the assumption of Proposition 1, minimum quality $v=0$ is available in the market in each period if $R(0, s)>c(0)$ for some $s \in S$, whereas if $R(0, s)<c(0)$ for all $s \in S$ the respective good is never available (due to lack of demand). In the borderline case $R\left(0, s_{\max }\right)=c(0)$, in any period $t$ minimum quality of the good may or may not be sold.

The intuition of Proposition 1 is as follows. By the proposition's assumption customers are not willing to pay the price $\hat{p}(v)$ that is necessary to provide the incentive to actually produce quality $v>0$ when profits per period are constant in time. Since positive quality can be sold only for some price below $\hat{p}(v)$, an equilibrium requires that along the equilibrium path profits of a firm that sells $v>0$ in some period $t$ increase in the future. Since profits can be positive in the future only if the respective firm provides again positive quality, the argument feeds on itself and profits have to increase ever more. In fact, it can be shown that 
with $t \rightarrow \infty$ profits must diverge. Since customers' expenses are uniformly bounded, this is not feasible and the proposition follows.

Even when customers are not willing to pay the prices $\hat{p}(v)$ for $v \in(0,1]$, they may be willing to pay the production $\operatorname{cost} c(v)<\hat{p}(v)$. In particular, it may be the case that every single customer prefers the highest feasible quality to all other alternatives when prices equal marginal cost, i.e., $\max [R(v, s)-c(v), 0]<R(1, s)-c(1)$ may hold for all $v<1$ and all $s \in S$. If this is the case, only the highest feasible quality would be consumed in the first best, whereas due to asymmetric information either only minimum quality is available in equilibrium or the good is not available at all.

Proposition 1 holds as well for the more general case where the payoff function $U(v, p, s)$ is any function $U:[0,1] \times \mathbb{R}_{+} \times S \rightarrow \mathbb{R}$ that is strictly decreasing in the price $p .{ }^{17}$ The proof of Proposition 1 shows that if $U[v, \hat{p}(v), s]<\max \{U[0, c(0), s], 0\}$ for all $v \in(0,1]$ and all $s \in S$, then in every Nash equilibrium in pure strategies positive quality $v>0$ is never available in the market. Moreover, Proposition 1 does not depend on the details of the game, such as simultaneous entry of firms, and extends to equilibria in mixed strategies.

\section{Equilibrium Prices and Incentive Constraints}

For the reasons explained in Section 2, we examine only stationary equilibria (in pure strategies) in the rest of the paper. Along any stationary equilibrium path, all incumbents' actions are constant. However, deviating strategies are not constrained to be stationary. If we restrict for each firm the whole strategy set to stationary strategies, we get a new game, which we call the restricted game. Although even for a stationary equilibrium of the original game all strategies have to be considered as possible deviations, the following lemma shows that it is actually sufficient to look only at stationary strategies.

Lemma 1. A strategy profile that constitutes a Nash equilibrium in pure strategies of the restricted game is also a Nash equilibrium in pure strategies of the original game. ${ }^{18}$

\footnotetext{
${ }^{17}$ If the parameter $s$ is interpreted as "income" thought of as a Hicksian "composite commodity", the payoff becomes $U(v, p, s)=u(v, s-p)$, which frequently is further simplified to $U(v, p, s)=w(v)(s-p)$, as, e.g., in Gabszewicz and Thisse $(1979,1980)$ and Shaked and Sutton $(1982,1983)$.

${ }^{18}$ Obviously, the converse also holds: if a strategy profile of stationary strategies constitutes a Nash equilibrium of the original game, it also constitutes a Nash equilibrium of the restricted game.
} 
Obviously, in a stationary equilibrium incumbents have positive profits, do not cheat and do not exit. For each quality $v \in[0,1]$ that is available in the market there can be only one price $p(v)$ and it must hold that $p(v) \geq \hat{p}(v)$, where $\hat{p}(v)$ is given by (3.2). Otherwise the respective firm(s) would cheat. Below we will derive a condition that implies the equality $p(v)=\hat{p}(v)$ for all intermediate quality levels $v \in(0,1)$. Consequently, under this (sufficient but non necessary) condition equilibrium prices of intermediate quality levels are completely determined by the incentive constraints (3.3), whereas customer preferences and the distribution of customer types only determine the quantities demanded, given (predetermined) equilibrium prices. In addition, the price for minimum quality $v=0$ is given by its cost $c(0)$. For maximum quality $v=1$ the incentive constraint determines the price $p(1)=\hat{p}(1)$ in two different circumstances. One case occurs when the incentive cost $\frac{\rho}{\varphi} \gamma$ is sufficiently large to make the price $\hat{p}(1)=c(1)+\frac{\rho}{\varphi} \gamma$ optimal (in the set $\{p \mid p \geq \hat{p}(1)\}$ of "feasible" prices) even for a firm that is the sole brand name in the market. The other case, explained in the following paragraph, is the one where two or more brand names offer quality $v=1$.

If at least two brand names offer the same quality $\bar{v}>0$, then Bertrand competition will drive the price $p(\bar{v})$ to "the lowest possible value." In the case of observable quality this lowest possible value is the marginal cost $c(\bar{v})$. In contrast, when quality is unobservable, the lowest possible value is $\hat{p}(\bar{v})$ in any stationary equilibrium, since a brand name that had announced quality $\bar{v}>0$ and charges a price $p(\bar{v})<\hat{p}(\bar{v})$ will cheat. Because of Assumption 3 (Customer Beliefs), customers will buy its product for a price below $\hat{p}(\bar{v})$ only if the price is $c(0)$. Thus, if the firm charges a price $p(\bar{v})<\hat{p}(\bar{v})$, its profit is zero, whereas it is positive if $p(\bar{v})=\hat{p}(\bar{v})$. Consequently, whenever two or more brand names offer the same quality $\bar{v}$ it must hold that $p(\bar{v})=\hat{p}(\bar{v})$ in any stationary equilibrium. ${ }^{19,}{ }^{20}$ Although it is implausible that two or more brand names offer the same intermediate quality $v \in(0,1)$,

\footnotetext{
${ }^{19}$ As Klein and Leffler (1981, p. 625) put it "... the quality-assuring price is, in effect, a minimum price constraint 'enforced' by rational consumers."

${ }^{20}$ Since brand names have no fixed costs of production, every brand name that has incurred the entry cost can stay in the market and guarantee itself a non-negative profit per period. Consequently, it is impossible that a brand name drives another brand name out of the market by undercutting $\hat{p}(\bar{v})$. In the case where (contrary to our model) brand names have fixed costs of production, a different argument gives the same result. With fixed costs, undercutting will trigger a war of attrition, and in wars of attrition the most plausible equilibria are those in mixed strategies. Since this implies expected payoffs of zero, whereas cheating gives strictly positive payoffs, the respective brand names will cheat. Because customers will recognize this, undercutting is not profitable.
} 
our analysis will show that for maximum quality $v=1$ this may well be the case.

The additional amount of money that an agent of type $s$ is willing to pay when the good is of highest rather than of lowest possible quality is $r(s) \equiv R(1, s)-R(0, s)$. It will be convenient to assume that types can be identified by this number, ${ }^{21}$ and we define types in this way for the rest of the paper. In order to avoid a change in the notation of types from $s$ to $r$, we assume, without loss of generality, that $r(s)$ was already the original way to define types, i.e., that the identity $s \equiv r(s)$ holds.

For the rest of the paper we assume that $R(\cdot, \cdot)$ is twice continuously differentiable and that $R_{v s}(\cdot, \cdot)>0$ for $v>0$, where subscripts of $R(\cdot, \cdot)$ always denote the respective partial derivatives. The assumption $R_{v s}(\cdot, \cdot)>0$ is a single crossing condition and means that types that have a higher utility difference between maximum and minimum quality also have a higher willingness to pay for additional quality in general, i.e., have a higher marginal willingness to pay for quality. Consequently, for any pair $v^{\prime \prime}, v^{\prime} \in[0,1], v^{\prime \prime}>v^{\prime}$, the difference in willingness to pay, $R\left(v^{\prime \prime}, s\right)-R\left(v^{\prime}, s\right)=\int_{v^{\prime}}^{v^{\prime \prime}} R_{v}(v, s) d v$, is strictly increasing in $s .^{22}$

Assumption 4 (Increasing Differences). Customers' willingness to pay function $R(\cdot, \cdot)$ is twice continuously differentiable and $R_{v s}(\cdot, \cdot)>0$ for $v>0$. That is, higher types have a higher willingness to pay for additional quality.

We provide a sufficient condition for the incentive constraint to determine the price charged by a firm that produces some quality $v \in(0,1)$ below the maximum quality. Specifically, we show that whenever it holds for all types $s \in S$ that $R_{v}(\bar{v}, s)>\gamma$ for some $\bar{v} \in(0,1)$, then $p(\bar{v})=\hat{p}(\bar{v})$. Consequently, if $R_{v}(v, s)>\gamma$ for all $v \in(0,1)$ and all $s \in S$, then $p(v)=\hat{p}(v)$ for all $v \in[0,1)$ since $p(0)=\hat{p}(0)=c(0)$ holds trivially. Substituting for $\hat{p}(v)$ gives $p(v)=c(v)+\frac{\rho}{\varphi} \gamma v=c(0)+\left(1+\frac{\rho}{\varphi}\right) \gamma v=c(0)+\alpha \gamma v$, where $\alpha$ is defined as $\alpha \equiv 1+\frac{\rho}{\varphi}=\frac{\varphi+\rho}{\varphi}>1$. Because of $R_{v s}(\cdot, \cdot)>0$, the condition $R_{v}(v, s)>\gamma$ for all $v \in(0,1)$ and all $s \in S$ is equivalent to $R_{v}\left(v, s_{\min }\right)>\gamma$ for all $v \in(0,1)$. Moreover, it is also equivalent to the condition that $R(v, s)-c(v)=R(v, s)-c(0)-\gamma v$ increases in $v$ for all $s \in S$; or, alternatively, that $v^{\prime}>v$ implies $R\left(v^{\prime}, s\right)-c\left(v^{\prime}\right)>R(v, s)-c(v)$ for all $v^{\prime}, v \in(0,1)$ and

\footnotetext{
${ }^{21}$ That is, if for two types, $s$ and $s^{\prime}$, it holds that $R(1, s)-R(0, s)=R\left(1, s^{\prime}\right)-R\left(0, s^{\prime}\right)$, then $s=s^{\prime}$.

${ }^{22}$ Except for points of inflection the converse also holds. Whenever for all $v^{\prime \prime}, v^{\prime} \in[0,1], v^{\prime \prime}>v^{\prime}$, the difference $R\left(v^{\prime \prime}, s\right)-R\left(v^{\prime}, s\right)=\int_{v^{\prime}}^{v^{\prime \prime}} R_{v}(v, s) d v$, is strictly increasing in $s$ for all $s \in S$, then $R_{v s}(\cdot, \cdot)>0$ except for isolated points $\tilde{v} \in[0,1]$. This follows because if $R_{v s}(v, s) \leq 0$ for all $v \in\left[v^{\prime}, v^{\prime \prime}\right]$ for some pair $v^{\prime}, v^{\prime \prime} \in[0,1], v^{\prime \prime}>v^{\prime}$, then $\frac{\partial\left[R\left(v^{\prime \prime}, s\right)-R\left(v^{\prime}, s\right)\right]}{\partial s}=\int_{v^{\prime}}^{v^{\prime \prime}} R_{v s}(v, s) d v \leq 0$.
} 
all $s \in S$. As a consequence, all agents prefer the highest feasible quality $v=1$ to any other quality (though not necessarily to abstention), if for all $v \in[0,1]$ prices $p(v)$ equal marginal $\operatorname{costs} c(v) .^{23}$

Proposition 2. If for some intermediate level of quality $\bar{v} \in(0,1)$ all customers' marginal willingness to pay for quality exceeds the "marginal cost of quality," i.e., $R_{v}(\bar{v}, \cdot)>\gamma$, then in any stationary equilibrium the price $p(\bar{v})$ for this level of quality is given by $p(\bar{v})=\hat{p}(\bar{v})$; that is, the price for quality $\bar{v}$ is determined by the incentive constraint. If for all intermediate levels of quality all customers' marginal willingness to pay for quality exceeds the "marginal cost of quality," i.e., $R_{v}(\cdot, \cdot)>\gamma$ for all $v \in(0,1)$, then in any stationary equilibrium the price $p(v)$ is given by $p(v)=\hat{p}(v)=c(0)+\alpha \gamma v$ for each level of quality $v \in[0,1)$ below the highest possible level. Thus, for each positive level of quality $v \in[0,1)$ below the highest possible level the price is determined by the incentive constraint. ${ }^{24}$

Thus, if customers have a sufficiently strong preference, relative to production cost, for higher quality, then prices for all quality levels $v \in[0,1)$ below 1 are determined by the sum of production and incentive cost. Customer preferences, as long as they satisfy $R_{v}(\cdot, \cdot)>\gamma$ for $v>0$, and the distribution of customer types only determine the quantities demanded, given the equilibrium prices (which are determined by the incentive constraints only). In addition, whenever two or more firms offer the highest possible quality $v=1$, it follows from

\footnotetext{
${ }^{23}$ If $R(\cdot, \cdot)$ is strictly concave in $v$ (i.e., if $R_{v v}(\cdot, \cdot)<0$ ), such a preference for the highest feasible quality is even equivalent to $R_{v}(\cdot, \cdot)>\gamma$ because then $R_{v}(v, \cdot) \leq \gamma$ for some $\bar{v} \in(0,1)$ implies $R_{v}(v, \cdot)<\gamma$ for all $v \in(\bar{v}, 1)$ and thus $R(\bar{v}, \cdot)-c(\bar{v})>R(v, \cdot)-c(v)$ for all $v \in(\bar{v}, 1)$. Notice that when $R(\cdot, \cdot)$ is strictly concave in $v, R(v, s)-c(v)=R(v, s)-c(0)-\gamma v$, achieves an interior maximum where $R_{v}(v, s)=\gamma$, provided such an interior maximum exists. Consequently, if $R(\cdot, \cdot)$ is strictly concave in $v$ and all customers prefer the highest feasible quality $v=1$ to any other quality at prices $p(v)=c(v)$, then it must hold that $R_{v}(v, \cdot)>\gamma$ for all $v \in(0,1)$.

${ }^{24}$ It is sufficient that $R_{v}(\bar{v}, s)>\gamma$ holds for the (unique) type $s(\bar{v})$ that solves $R_{v}(\bar{v}, s)-R_{v}(0, s)=\alpha \gamma \bar{v}$ (thus $s(\bar{v})$ is the "indifferent type" defined by $R_{v}(\bar{v}, s)-\hat{p}(\bar{v})=R_{v}(0, s)-c(0)$ ), whenever such a type exists. Because of $R_{v s}(\bar{v}, s)>0$, this implies $R_{v}(\bar{v}, s)>\gamma$ for all higher types $s>s(\bar{v})$, but for lower types $s<s(\bar{v})$ it may hold that $R_{v}(\bar{v}, s) \leq \gamma$. If a type $s(\bar{v})$ does not exist, either $R_{v}(\bar{v}, s)-R_{v}(0, s)<\alpha \gamma \bar{v}$ for all $s \in S$ and no type will demand quality $\bar{v}$ at the price $\hat{p}(\bar{v})$, or $R_{v}(\bar{v}, s)-R_{v}(0, s)>\alpha \gamma \bar{v}$ for all $s \in S$ and then the assumption $R_{v}(\bar{v}, \cdot)>\gamma$ is needed. If for each $\bar{v} \in(0,1)$ the type $s(\bar{v})$ exists and satisfies $R_{v}(\bar{v}, s)>\gamma$, then $p(\bar{v})=\hat{p}(\bar{v})$ for all $\bar{v} \in(0,1)$. Moreover, the proposition can be extended to the case where the strict inequality in $R_{v}(\bar{v}, s)>\gamma$ is replaced by the weak inequality.
} 
Bertrand competition that the price for maximum quality $v=1$ is also determined by the incentive constraint, i.e., $p(1)=\hat{p}(1)$.

\section{Equilibrium With Convex Willingness to Pay}

The shape of customers' willingness to pay functions $R(v, s)$, specifically whether they are convex or concave with respect to quality $v$, has a significant effect on the equilibrium. We restrict our analysis to the two cases where these functions are either convex or concave with respect to quality $v$ for all $s \in S .{ }^{25}$ First, we analyze the case where customers' willingness to pay $R(v, s)$ is convex in $v$, i.e., $R_{v v}(\cdot, \cdot) \geq 0$ for all $s \in S$. That includes, in particular, the subcase where $R(\cdot, \cdot)$ is linear in $v$. We show that in this convex case at most the two extreme quality levels, $v=0$ and $v=1$, are available in the market. If two or more firms can cover their entry cost, all will offer quality $v=1$ for the price $\hat{p}(1) \cdot{ }^{26}$ A plausible assumption is that higher types are willing to pay more for maximum quality, that is, $R(1, \cdot)$ is increasing in $s$. In this case, the interval $S=\left[s_{\min }, s_{\max }\right]$ can be partitioned into a point $\bar{s}$ and the two subintervals, $\left[s_{\min }, \bar{s}\right)$ and $s \in\left(\bar{s}, s_{\max }\right]$, such that all types $s \in\left(\bar{s}, s_{\max }\right]$ consume quality $v=1$, whereas all types $s \in\left[s_{\min }, \bar{s}\right)$ either abstain from consuming the good or consume quality $v=0$. Whenever $\bar{s} \in\left(s_{\min }, s_{\max }\right)$, customer type $\bar{s}$ is indifferent between consuming quality $v=1$ and the better one of the alternatives abstention and consumption of quality $v=0$.

Proposition 3. Assume that customers' willingness to pay $R(\cdot, s)$ is convex in $v$, i.e., $R_{v v}(\cdot, s) \geq 0$, for all $s \in S$. Then in every stationary equilibrium at most the quality levels $v=0$ and $v=1$ are available in the market. If the market can accommodate two or more firms that offer positive quality, the only equilibrium in stationary strategies is that all those firms offer $v=1$ for the price $p(1)=\hat{p}(1)=c(0)+\alpha \gamma$. If customers' willingness to pay for maximum quality $R(1, \cdot)$ is strictly increasing in type $s$, there exists a customer type

\footnotetext{
${ }^{25}$ Some customers will never demand positive quality at prices $p(v) \geq \hat{p}(v)$ and, thus, the shape of their willingness to pay functions - whether they are convex, concave or neither - is irrelevant. Specifically, if for a customer type $\tilde{s}$ it holds that $R(v, \tilde{s})-\hat{p}(v)<\max [R(0, \tilde{s})-c(0), 0]$ for all $v \in(0,1]$, it follows from the incentive constraint (3.3) that this type will never demand positive quality. Thus we could limit any assumption on the shape of $R(\cdot, \cdot)$ to "relevant" types.

${ }^{26}$ Since we have normalized the population to have measure 1 , the entry cost has to be measured relative to the size of the population.
} 
$\bar{s} \in S$ such that all types $s \in\left[s_{\min }, \bar{s}\right)$ either abstain from consuming the good or consume quality $v=0$, and all types $s \in\left(\bar{s}, s_{\max }\right]$ consume quality $v=1$. Provided two or more firms offer positive quality, the (indifferent) customer type $\bar{s}$ decreases strictly with $\alpha$ for $\bar{s} \in\left(s_{\min }, s_{\max }\right)$.

Interestingly, more demand may reduce the price $p(1)$. With weak demand only one brand name is able to cover the entry cost, and in general a (monopoly) price $p^{M}(1)>\hat{p}(1)$ will be optimal for the single brand name. In contrast, with stronger demand two or more brand names are able to cover the entry cost and thus the equilibrium price is $p^{B}(1)=$ $\hat{p}(1)<p^{\prime}(1)$ because of Bertrand competition. This gives the following corollary.

Corollary 1. If customers' willingness to pay $R(\cdot, s)$ is convex in $v$ for all $s \in S$ (i.e., $\left.R_{v v}(\cdot, \cdot) \geq 0\right)$, then an increase in some or all customers' willingness to pay for quality $v=1$ may reduce the equilibrium price of quality $v=1$.

Is the equilibrium outcome constrained efficient in the sense that a planner who does not have more information than the customers and cannot influence the parameters of the model, cannot improve the outcome? In general not, since the planner would allow only one brand name to enter because of the positive entry cost. However, if in the stationary equilibrium there is only one brand name but the price for quality $v=1$ is nevertheless $\hat{p}(1)$, then the equilibrium outcome is constrained efficient. That is, the equilibrium outcome is constrained efficient with respect to quality choice and prices, provided $p(1)=\hat{p}(1)$. This holds because like the market the planner has to provide incentives for the firms not to cheat. Thus, when setting prices the planner is constrained by the incentive constraints (3.3). Of course, policy may increase the detection parameter $\varphi$ (at some cost) and therefore reduce prices (and firm's profits). However, the lack of intermediate qualities $v \in(0,1)$ in the market is constrained efficient even regardless of the detection parameter $\varphi$. This follows because linearity of unit cost $c(v)$ and convexity of willingness to pay $R(v, s)$ in quality $v$ imply that for any value of the detection parameter $\varphi$ consumer welfare and total profits can be maximized with just the two qualities $v=0$ and $v=1$. Even the first-best can be achieved without any intermediate quality levels being available in the market.

It is useful to compare our model with one that is identical except that quality is observable and unit production cost of quality $v \in[0,1]$ is given by $c(v)=c(0)+\alpha \gamma v$. That is, for the comparison we consider the market for an inspection good that has (no incentive costs 
but) production costs which are identical to the sum of production and incentive costs of the experience good considered so far. In all other respects, in particular regarding preferences and entry cost, the two models are identical. At least when customers' willingness to pay $R(\cdot, s)$ is strictly convex in $v$ (i.e., $R_{v v}(\cdot, s)>0$ ), the proof of Proposition 3 can be applied to this case as well, although with a slight modification. ${ }^{27}$ It follows that only one brand name can be in the market, because with two or more brand names all will offer $v=1$ for the price $\hat{p}(1)=c(0)+\alpha \gamma$ that equals unit cost and gives zero profits. Since the brand names could not cover the positive entry cost, only one brand name can be in the market in a stationary equilibrium. The single brand name will offer quality $v=1$ for a price $p(1)>\hat{p}(1)$ and customers will be worse off than in the case where total unit cost $c(v)=c(0)+\alpha \gamma v$ consists of production cost $c(0)+\gamma v$ and incentive cost $(\alpha-1) \gamma v=\frac{\rho}{\varphi} \gamma v$.

\section{Equilibrium With Concave Willingness to Pay}

In this section, we consider the case where each customer's willingness to pay $R(\cdot, \cdot)$ is concave in $v$, i.e., $R_{v v}(\cdot, \cdot) \leq 0$. Whenever $R(\cdot, \cdot)$ is linear in $v$ the results of the previous section apply, and this is also true for some degenerate cases (e.g., when $R(\cdot, s)$ is non-linear only for types $s$ that will never demand positive quality). If $R(\cdot, \cdot)$ is strictly concave in $v$, the model becomes similar to a location model. ${ }^{28}$. Depending on customer preferences, the distribution of customer types, and other parameters, many outcomes are possible. Moreover, because of the discontinuity associated with Bertrand competition an equilibrium need not exist.

We provide sufficient conditions for a lack of variety in the sense that no or at best relatively few firms offer an intermediate quality level even though willingness to pay is concave. The intuition for this result is that with a skewed type distribution it is more

\footnotetext{
${ }^{27}$ The only difference is that when quality $\bar{v}<1$ and price $p(\bar{v})$ are increased to $v=1$ and $p(1)=$ $p(\bar{v})+(1-\bar{v}) \alpha \gamma$, respectively, profit per customer $p(1)-c(0)-\alpha \gamma=p(\bar{v})+(1-\bar{v}) \alpha \gamma-c(0)-\alpha \gamma=$ $p(\bar{v})-c(0)-\alpha \gamma \bar{v}$ does not increase but remains constant.

${ }^{28}$ If $R_{v v}(\cdot, \cdot)<0$ and prices are given by $p(v)=\hat{p}(v)=c(0)+\alpha \gamma v$ for all $v \in[0,1], R(v, s)-p(v)$ has an interior maximum where $R_{v}(v, s)=\alpha \gamma$, provided an interior maximum exists. If an interior maximum does not exist, either $R(0, s) \leq \alpha \gamma$ and $\arg \max [R(v, s)-p(v)]=0$, or $R(1, s) \geq \alpha \gamma$ and $\arg \max [R(v, s)-p(v)]=1$. Thus, we can define the "location" $v(s)$ of customer $s$ to be the solution of $R_{v}(v, s)=\alpha \gamma$ if such a solution exists, to be $v(s)=0$ if $R(0, s) \leq \alpha \gamma$, and to be $v(s)=1$ if $R(1, s) \geq \alpha \gamma$. However, if $R(v(s), s)<\hat{p}(v(s))$, type $s$ prefers not to buy the product at all.
} 
profitable to share the high price market for maximum quality with competitors than to offer an intermediate quality level. Since the price for maximum quality cannot fall below $\hat{p}(1)>c(1)$, the effect of competition is limited. Provided two or more firms already offer maximum quality, entry into this market does not decrease the price although it exceeds marginal cost. Thus, the incentive to differentiate is significantly reduced. If, given the entry cost, the overall market for positive quality levels can accommodate only few firms, all (or most) incumbents may offer maximum quality.

For the two propositions of this section we employ the plausible assumption that customers' willingness to pay for maximum quality $v=1$ is strictly increasing in type, i.e., $R_{s}(1, \cdot)>0$. If at least two firms offer quality $v=1$, Bertrand competition implies $p(1)=$ $\hat{p}(1)$. Since $p(v) \geq \hat{p}(v)$ for all $v \in[0,1]$, at the price $p(1)=\hat{p}(1)$ every type $s \in S$ that satisfies the two conditions $R_{v}(1, s) \geq \alpha \gamma$ and $R(1, s)>\hat{p}(1)$ demands quality $v=1$, regardless of the availability of other quality levels. Because of Assumption 4 and $R_{s}(1, \cdot)>0$, if some type $s$ demands quality $v=1$, every type $s^{\prime}>s$ does so as well. Consequently, there exists a type $s_{1} \in S$ such that if $p(1)=\hat{p}(1)$, all $s>s_{1}$ demand maximum quality $v=1$ regardless of the availability of other quality levels and their prices $p(v) \geq \hat{p}(v)$, whereas for all types $s<s_{1}$ this is not the case. These types $s<s_{1}$ either prefer some quality $v \in[0,1)$ for the price $p(v)=\hat{p}(v)$ or prefer not to buy at all. Specifically, we define $s_{1}$ in the following way. If the two conditions $R_{v}(1, s) \geq \alpha \gamma$ and $R(1, s) \geq \hat{p}(1)$ have a solution $s^{\prime}$ such that at least one inequality holds as equality, then $s_{1}=s^{\prime}$. If such a solution does not exist but it holds that $R_{v}\left(1, s_{\min }\right)>\alpha \gamma$ and $R\left(1, s_{\min }\right)>\hat{p}(1)$, then $s_{1}=s_{\min }$. Otherwise, for each $s \in S$ at least one of the two inequalities, $R_{v}(1, s) \geq \alpha \gamma$ and $R(1, s) \geq \hat{p}(1)$, is violated and we define $s_{1}=s_{\max }$. It is easy to show that at the price $p(1)=\hat{p}(1)$ demand for maximum quality $v=1$ is bounded from below by $1-F\left(s_{1}\right)$, regardless of the availability of other quality levels and their (incentive compatible) prices. ${ }^{29}$

Next we define a type $s_{0}$ such that every "lower" type $s<s_{0}$ (which exists only if $\left.s_{0}>s_{\text {min }}\right)$ never demands positive quality. Because of $p(v) \geq \hat{p}(v)=p(0)+\alpha \gamma v$ for all $v \in[0,1]$ and $R_{v v}(\cdot, \cdot) \leq 0$, a type $s$ with $R_{v}(0, s)<\alpha \gamma$ will always prefer minimum quality $v=0$ to any positive quality since for every $v>0$ it holds that $R(v, s)-p(v)<$ $R(0, s)+\alpha \gamma v-\hat{p}(v)=R(0, s)-p(0)$. If $R_{v}(0, s)=\alpha \gamma$ has a unique solution $s^{\prime \prime}$, we define $s_{0}$ by $s_{0}=s^{\prime \prime}$, and if it has more than one solution, let $s_{0}$ be the minimum of those. If

\footnotetext{
${ }^{29}$ The proof of Proposition 4 in the Appendix contains a rigorous derivation.
} 
$R_{v}(0, s)=\alpha \gamma$ has no solution, either $R_{v}\left(0, s_{\text {min }}\right)>\alpha \gamma$ (which implies $R_{v}(0, s)>\alpha \gamma$ for all $s$ ) or $R_{v}\left(0, s_{\max }\right)<\alpha \gamma$ (which implies $R_{v}(0, s)<\alpha \gamma$ for all $s$ ). We define $s_{0}=s_{\min }$ if $R_{v}\left(0, s_{\min }\right)>\alpha \gamma$, and $s_{0}=s_{\max }$ if $R_{v}\left(0, s_{\max }\right)<\alpha \gamma$. It follows that at most $1-F\left(s_{0}\right)$ customers will ever demand positive quality. Moreover, if quality $v=1$ is available for the price $p(1)=\hat{p}(1)$, demand for intermediate quality levels $v \in(0,1)$ is bounded from above by $F\left(s_{1}\right)-F\left(s_{0}\right)$.

For reasons that will become clear below, we are interested in the situation where $F\left(s_{1}\right)-$ $F\left(s_{0}\right)$ is smaller than $1-F\left(s_{1}\right)$. This will be the case whenever prices $\hat{p}(v)$ are relatively high, the distribution of types is skewed to the right (which his consistent with the distributions of income and of wealth both being skewed to the right), and the willingness to pay is not too concave in $v$. Under these conditions $F\left(s_{1}\right)-F\left(s_{0}\right)$ will be smaller than $1-F\left(s_{1}\right)$. Thus, for many cases $1-F\left(s_{1}\right)>F\left(s_{1}\right)-F\left(s_{0}\right)$ seems a plausible assumption. In fact, the difference between the two expressions may be significant, and thus the ratio $\frac{1-F\left(s_{1}\right)}{F\left(s_{1}\right)-F\left(s_{0}\right)}$ may be considerably larger than 1 . Let $\lambda$ denote $\frac{1-F\left(s_{1}\right)}{1-F\left(s_{0}\right)}$, which is the probability that conditional on $s \geq s_{0}$ a randomly drawn customer is of type $s \geq s_{1}$. Since $\lambda=\frac{1-F\left(s_{1}\right)}{1-F\left(s_{0}\right)}, 1-\lambda=\frac{F\left(s_{1}\right)-F\left(s_{0}\right)}{1-F\left(s_{0}\right)}$.

If for all intermediate levels of quality all customers' marginal willingness to pay for quality exceeds the "marginal cost of quality", i.e., $R_{v}(\cdot, \cdot)>\gamma$ for all $v \in(0,1)$, then $p(v)=\hat{p}(v)$ for all $[0,1)$ because of Proposition 2. Consequently, profit per customer is maximized at $v=1$, since $p(1)-c(1) \geq \hat{p}(1)-c(1)=(\alpha-1) \gamma>(\alpha-1) \gamma v=\hat{p}(v)-c(v)$ for all $v \in[0,1)$. As an illustration consider the case $1-F\left(s_{1}\right)=2\left[F\left(s_{1}\right)-F\left(s_{0}\right)\right]$, i.e., $\lambda=\frac{2}{3}$.

If there are $N=2$ brand names in the market and $\lambda=\frac{2}{3}$, it cannot be a stationary equilibrium that each offers some (identical or different) intermediate quality level, as the following argument shows. Since their total demand is at most $1-F\left(s_{0}\right)$, their combined profit per period is less than $\left[1-F\left(s_{0}\right)\right](\alpha-1) \gamma$. Consequently, at least one brand level has a profit per period that is less than $\frac{1}{2}\left[1-F\left(s_{0}\right)\right](\alpha-1) \gamma=\frac{1}{2}\left[\frac{1-F\left(s_{1}\right)}{\lambda}\right](\alpha-1) \gamma=$ $\frac{3}{4}\left[1-F\left(s_{1}\right)\right](\alpha-1) \gamma<\left[1-F\left(s_{1}\right)\right](\alpha-1) \gamma$. If the respective brand name offers quality $v=1$ for the price $p(1)=\hat{p}(1)$, its profit per period exceeds $\left[1-F\left(s_{1}\right)\right][p(1)-c(1)] \geq$ $\left[1-F\left(s_{1}\right)\right](\alpha-1) \gamma$. Thus, the respective brand name can increase its payoff by switching to quality $v=1$. Moreover, it cannot be a stationary equilibrium either that one brand name offers an intermediate quality level $v \in(0,1)$ and the other offers maximum quality $v=1$ for the price $p(1)=\hat{p}(1)$. The reason is that the profit per period of the brand name that offers 
$v<1$ is less than $\left[F\left(s_{1}\right)-F\left(s_{0}\right)\right](\alpha-1) \gamma v<\frac{1}{2}\left[1-F\left(s_{1}\right)\right](\alpha-1) \gamma$. Hence the respective brand name is better off, if it offers maximum quality $v=1$ as well. This argument also shows that for $\lambda=\frac{2}{3}$ and $N=2$ it is always an equilibrium (assuming that the entry cost $\eta$ is consistent with $N=2$ in equilibrium) that both brand names offer maximum quality $v=1$, which implies that the price is $p(1)=\hat{p}(1)$ because of Bertrand competition. In addition, it can also be an equilibrium that one brand name offers an intermediate quality level $v \in(0,1)$ for the price $p(v)=\hat{p}(v)$ and the other offers maximum quality for some price $p(1)>\hat{p}(1)$, but this requires quite specific assumptions and does not hold generally. ${ }^{30}$

If there are $N=3$ brand names in the market and $\lambda=\frac{2}{3}$, at least 2 brand names will offer quality $v=1$ and thus the price is $p(1)=\hat{p}(1)$. The reason is as follows. If all 3 firms offer intermediate quality, at least one has a profit per period below $\frac{1}{3}\left[1-F\left(s_{0}\right)\right](\alpha-1) \gamma<$ $\frac{1}{2}\left[1-F\left(s_{0}\right)\right](\alpha-1) \gamma<\left[1-F\left(s_{1}\right)\right](\alpha-1) \gamma($ the second inequality has been derived above) and thus has a higher payoff, if it offers maximum quality for the price $p(1)=\hat{p}(1)$. If two firms offer intermediate quality and the third offers maximum quality for some price $p(1)>\hat{p}(1)$, at least one firm offering intermediate quality has a profit per period below $\frac{1}{2}\left[1-F\left(s_{0}\right)\right](\alpha-1) \gamma<\left[1-F\left(s_{1}\right)\right](\alpha-1) \gamma$ and thus is better off, if it offers maximum quality for the price $p(1)=\hat{p}(1)$. If two firms offer intermediate quality and the third offers maximum quality for the price $p(1)=\hat{p}(1)$, at least one firm offering intermediate quality has a profit per period below $\frac{1}{2}\left[F\left(s_{1}\right)-F\left(s_{0}\right)\right](\alpha-1) \gamma=\frac{1}{4}\left[1-F\left(s_{1}\right)\right](\alpha-1) \gamma<$ $\frac{1}{2}\left[1-F\left(s_{1}\right)\right](\alpha-1) \gamma$, and thus, again, it is better off, if offers maximum quality for the price $p(1)=\hat{p}(1)$.

If there are $N=4$ brand names in the market and $\lambda=\frac{2}{3}$, a similar argument shows that at least 3 brand names will offer quality $v=1$. Thus, in the example brand names tend to provide maximum quality rather than intermediate quality. The following proposition

\footnotetext{
${ }^{30}$ Specifically, the firm offering $v<1$ for the price $p(v)=\hat{p}(v)$ must make a higher profit than the one that offers $v=1$ for some price $p_{1}>\hat{p}(1)$ because otherwise the former could increase its payoff by undercutting the latter (notice that the firm offering $v=1$ cannot undercut its competing brand name because $v<1$ is sold for the lowest possible price $p(v)=\hat{p}(v))$. Moreover, if the firm that provides $v<1$ offers instead maximum quality $v=1$ for some price $p_{2} \in\left[\hat{p}(1), p_{1}\right)$ it gets the whole market for quality $v=1$ and its only effective competitors are no names offering minimum quality $v=0$ for the price $c(0)$. Nevertheless the respective brand name's profit must not exceed the one it gets from offering intermediate quality $v<1$ for the price $\hat{p}(v)$. These necessary (but not sufficient) conditions illustrate that only under very specific circumstances an equilibrium where one of the two brand names offers intermediate quality exists.
} 
generalizes this observation.

Proposition 4. Consider the case where each customer's willingness to pay is concave in $v$, i.e., $R_{v v}(\cdot, \cdot) \leq 0$. Assume that customers' willingness to pay for maximum quality is strictly increasing in type $s$, i.e., $R_{s}(1, \cdot)>0$; and that for all intermediate levels of quality all customers' marginal willingness to pay for quality exceeds the "marginal cost of quality," i.e., $R_{v}(\cdot, \cdot)>\gamma$ for all $v \in(0,1)$. Then in every stationary equilibrium with $N \geq \frac{1}{\lambda}+1$ brand names in the market (which implies $N \geq 2$ ) the price for maximum quality $v=1$ is $p(1)=\hat{p}(1)$, and the number of brand names that offer maximum quality is at least $n>\lambda(N+1)-1$ for $\lambda<1$ and is $N$ for $\lambda=1 .^{31}$ Moreover, in every stationary equilibrium with $N \in\left[3, \frac{\lambda}{1-\lambda}\right]$ brand names in the market (which implies $\lambda \geq \frac{3}{4}$ ) all $N$ brand names in the market offer maximum quality $v=1$ for the price $p(1)=\hat{p}(1) \cdot{ }^{32}$

The number of brand names that offer maximum quality will frequently exceed its lower bound $\lambda(N+1)-1$ considerably. Without more specific assumptions on the willingness to pay functions it is impossible to derive tight bounds on demand for maximum and intermediate quality, respectively. In most cases the term $\left[1-F\left(s_{1}\right)\right]$ will significantly underestimate demand for quality $v=1$, while simultaneously the term $\left[F\left(s_{1}\right)-F\left(s_{0}\right)\right]$ will significantly overestimate demand for intermediate qualities. Moreover, since intermediate quality $v<1$ can be arbitrarily close to 1 , the fact that profits per customer decrease with quality $v$ cannot be exploited. Therefore, the proposition's result that brand names will provide exclusively or at least predominantly maximum quality can be expected to hold for considerably lower values of $\lambda=\frac{1-F\left(s_{1}\right)}{1-F\left(s_{0}\right)}$ than suggested by Proposition 4 .

Under the conditions of Proposition 4 brand names tend to provide maximum quality $v=1$ rather than an intermediate quality $v \in(0,1)$. For example, if $\lambda=\frac{2}{3}$, in a stationary equilibrium where $N=2$ no intermediate quality will be available in the market. But even when there are many brand names in the market, only relatively few intermediate qualities

\footnotetext{
${ }^{31}$ Notice that the inequality $n>\lambda(N+1)-1$ is equivalent to $\frac{n+1}{N+1}>\lambda$, which gives a lower bound to the "modified share" of firms that offer maximum quality.

${ }^{32}$ All stationary equilibria where $N \geq 2$ brand names are in the market and offer maximum quality, are equivalent from the customers' point of view. They differ only with respect to the identity of the firms. All stationary equilibria where $N=1$ brand name is in the market and offers maximum quality, are also equivalent from the customers' point of view, but if the sole brand name charges a price $p(1)>\hat{p}(1)$ customers are worse off than in stationary equilibria with $N \geq 2$ brand names offering maximum quality.
} 
will be available. For example, if $\lambda=\frac{2}{3}$, in a stationary equilibrium where $N=8$ at most 2 brand names will offer intermediate quality levels, whereas at least 6 brand names offer maximum quality. In fact, in most cases $\lambda=\frac{2}{3}$ and $N=8$ will imply that 7 brand names offer maximum quality and only one offers some intermediate level. ${ }^{33}$ Thus, although some intermediate quality levels may be offered when customer's willingness to pay is concave in $v$, they will be inefficiently few. Moreover, since profit per customer $\hat{p}(v)-c(v)=(\alpha-1) \gamma v$ increases in quality $v$, the intermediate quality levels that are actually available will be biased towards maximum quality $v=1$. In contrast, in the second-best every brand name would offer a different level of quality and the different quality levels would be spread out over the interval $(0,1]$.

The assumption that for all positive levels of quality all customers' marginal willingness to pay for quality exceeds the "marginal cost of quality" is used only to make sure that profits per customer are maximal at $v=1$, which follows from the assumption's implication that $p(v)=\hat{p}(v)$ for all $[0,1)$. Even when customers' marginal willingness to pay for quality is lower than required by the assumption, profit per customer may well be maximal at $v=1$ because optimal prices for intermediate quality levels may not exceed $\hat{p}(v)$ significantly, if at all. And if the optimal price for an intermediate quality level $v$ does exceed $\hat{p}(v)$ significantly, this may lead to low demand and the difference in profit per customer may be compensated by a higher number of customers at $v=1$. Whenever the distribution of types is sufficiently skewed to the right, we can expect brand names to concentrate at maximum quality $v=1$ and not to spread out over intermediate quality levels, as would be efficient.

As pointed out above, because of the discontinuity associated with Bertrand competition an equilibrium need not exist. Proposition 4 circumvents this issue. In the rest of this section we address this problem and provide a sufficient condition for existence of a stationary equilibrium where all brand names in the market offer maximum quality $v=1$. In the proof of Proposition 3 it is shown that if customers' willingness to pay for maximum quality is strictly increasing in type $s$, i.e., if $R_{s}(1, \cdot)>0$, there exists a unique type $\bar{s} \in S$ that solves the equation $R(1, \bar{s})-\hat{p}(1)=\max [R(0, \bar{s})-c(0), 0]$, provided $R\left(1, s_{\max }\right)-p(1) \geq$

\footnotetext{
${ }^{33}$ This follows from the fact that the bounds used for the proof of Proposition 4 are not tight, as explained in the previous paragraph. If $N$ is sufficiently large, such that more than 1 brand name may offer intermediate quality (as with $N=8$ ), there is an additional loss of tightness: the proof does not exploit the fact that the profit of the least profitable firm among several firms that all offer intermediate qualities will be below the average profit of those firms.
} 
$\max \left[R\left(0, s_{\max }\right)-c(0), 0\right]$ and $R\left(1, s_{\min }\right)-p(1) \leq \max \left[R\left(0, s_{\min }\right)-c(0), 0\right]$. Existence and uniqueness of the type $\bar{s}$ does not depend on the convexity of $R(\cdot, \cdot)$ in $v$ that is assumed for Proposition 3. If $R\left(1, s_{\max }\right)-p(1)<\max \left[R\left(0, s_{\max }\right)-c(0), 0\right]$ type $\bar{s}$ is defined as $\bar{s}=s_{\max }$, and if $R\left(1, s_{\min }\right)-p(1)>\max \left[R\left(0, s_{\min }\right)-c(0), 0\right]$ type $\bar{s}$ is defined as $\bar{s}=s_{\min }$. All types $s \in\left[s_{\min }, \bar{s}\right)$ prefer to buy quality $v=0$ for the price $c(0)$ or not to buy at all to buying quality $v=1$ for the price $\hat{p}(1)$, whereas all types $s \in\left(\bar{s}, s_{\text {max }}\right]$ prefer to buy quality $v=1$ for the price $\hat{p}(1)$ to buying quality $v=0$ for the price $c(0)$ and to not buying at all. Consequently, if only the extreme quality levels $v=0$ and $v=1$ are available in the market and prices are $p(0)=c(0)$ and $p(1)=\hat{p}(1)$, demand for quality $v=1$ is given by $1-F(\bar{s})$. If $N \geq 2$ brand names are in the market and all offer $v=1$, the price is $p(1)=\hat{p}(1)$ and the profit per period of each brand name is $\frac{1}{N}[1-F(\bar{s})](\alpha-1) \gamma$. Under the assumptions of Proposition 4, if one of the brand names deviates and offers some intermediate quality $v \in(0,1)$, its profit per period is less than $\left[F\left(s_{1}\right)-F\left(s_{0}\right)\right](\alpha-1) \gamma$. Thus, if $\left[F\left(s_{1}\right)-F\left(s_{0}\right)\right](\alpha-1) \gamma \leq \frac{1}{N}[1-F(\bar{s})](\alpha-1) \gamma$, no firm will deviate.

In any stationary equilibrium each brand name in the market must be able to cover the entry $\operatorname{cost} \eta$, which means that its profit per period must be at least $\eta \rho$ (where $\rho$ denotes the discount or interest rate). The constellation where $N \geq 2$ brand names are in the market and all offer maximum quality $v=1$ for the price $p(1)=\hat{p}(1)$, is a stationary equilibrium if three conditions hold: (i) each brand name in the market is at least able to cover the entry cost, (ii) an additional brand name, if it entered, could at best just cover the entry cost and thus cannot get a positive payoff, and (iii) no brand name in the market can increase its profit per period by deviating from maximum quality $v=1$ to some lower quality level. The following proposition provides sufficient conditions (a) for the existence of a stationary equilibrium where all brand names in the market offer maximum quality, and (b) for the conclusion that in every stationary equilibrium all brand names in the market offer maximum quality.

Proposition 5. Consider the case where each customer's willingness to pay is concave in $v$, i.e., $R_{v v}(\cdot, \cdot) \leq 0$. Assume that customers' willingness to pay for maximum quality is strictly increasing in type $s$, i.e., $R_{s}(1, \cdot)>0$; and that for all intermediate levels of quality all customers' marginal willingness to pay for quality exceeds the "marginal cost of quality," i.e., $R_{v}(\cdot, \cdot)>\gamma$ for all $v \in(0,1)$. If the two conditions $\frac{1}{N+1}[1-F(\bar{s})](\alpha-1) \gamma \leq$ $\eta \rho \leq \frac{1}{N}[1-F(\bar{s})](\alpha-1) \gamma$ and $\left[F\left(s_{1}\right)-F\left(s_{0}\right)\right](\alpha-1) \gamma \leq \eta \rho$ are both satisfied for some 
$N \geq 2$, there exists a stationary equilibrium where $N$ brand names are in the market and all offer $v=1$ for the price $p(1)=\hat{p}(1)$. Whenever, in addition, the first condition implies $N \geq 3$, all $N$ brand names in the market offer $v=1$ for the price $p(1)=\hat{p}(1)$ in every stationary equilibrium.

If Proposition 5 holds, the market for each specific intermediate quality level $\bar{v} \in(0,1)$ is too "thin" (for high $\bar{v}$ ) or too unprofitable (for low $\bar{v}$ ) to justify entry, given the availability of minimum and maximum quality for the prices $p(0)=c(0)$ and $p(1)=\hat{p}(1)$, respectively. Although many customers may prefer some intermediate quality, every particular level of intermediate quality would attract only a limited number of customers or generate only an insignificant profit per customer, and thus would result in an insufficient profit relative to the entry cost. Since for all $v \in(0,1)$ the price is $\hat{p}(v)$, profit per customer is proportional to $v$, and consequently for small $v$ the associated profit is low even when demand is high.

Existence of an equilibrium with one or more firms offering intermediate quality levels depends on details of customers' willingness to pay functions and of the distribution of types. The general level of our analysis with respect to these concepts prevents us from further examining this issue.

\section{Conclusions}

In many markets with asymmetric information about product quality, e.g., in some markets for agricultural produce and food products, quality is generally low, and high quality is either impossible to find or extremely expensive. Motivated by this casual observation, we considered a model of vertical product differentiation where before purchase the respective good's quality is unobservable to buyers, a continuum of quality levels is technologically feasible, and minimum quality is supplied under competitive conditions. After purchase the true quality of the good is revealed with positive probability. For each feasible quality level, except for the minimum, the price must exceed marginal cost in order to provide incentives for the respective firm not to produce lower quality than announced. Our analysis shows that if customers have a strong preference for high quality relative to production cost, equilibrium prices are completely determined by incentive constraints for all quality levels, except for the maximum. Consequently, for those quality levels customer preferences and the distribution of customer types only determine the quantities demanded, given equilibrium prices, but not 
the prices themselves. Moreover, if the information problem is sufficiently severe, no positive quality is available in the market even though all customers may prefer maximal quality to any other quality when each quality level is sold for a price that is equal to its unit cost.

The shape of customers' willingness to pay functions - whether they are convex or concave with respect to quality - has a significant effect on the equilibrium. When each customer's willingness to pay for quality is convex with respect to quality, at most two levels of quality, the lowest and the highest one among the technologically feasible levels, are available in the market, and this is constrained efficient. When customers' willingness to pay for quality is concave (but not linear), the model becomes similar to a location model and an equilibrium may not even exist. Existence of an equilibrium and its properties depend on details of customers' willingness to pay functions and the distribution of types. We investigated the case where the type distribution is skewed to the right and demonstrated that under plausible conditions firms that offer above minimum quality tend to concentrate at maximum quality $v=1$ rather than to spread out over all above minimum quality levels, as would be efficient. Only few firms, if any, will offer intermediate quality levels. Indeed, we provided sufficient conditions for the existence of an equilibrium where all brand names in the market offer maximum quality, and for the uniqueness of this equilibrium outcome. 


\section{Appendix}

Proof of Proposition 1: The proof is by contradiction. Assume that there exists a Nash equilibrium in pure strategies where in some period $t$ some firm offers some quality $v_{t}>0$ at a price $p_{t}$ such that sales $x_{t}$ are positive. The firm will not cheat along the equilibrium path (and thus we need not distinguish between announced and actual quality levels). Because of this and because we consider only pure strategies, the respective firm's sales are deterministic along the equilibrium path. Denote equilibrium sales by $x_{\tau} \geq 0$, equilibrium prices by $p_{\tau} \geq 0$, and equilibrium quality levels by $v_{\tau} \in[0,1], \tau \in\{t, t+1, \ldots\}$. Along the equilibrium path the firm's payoff from any period $\tau \in\{t, t+1, \ldots\}$ onwards is $V_{\tau} \equiv \sum_{s=\tau}^{\infty} \delta^{s+1-\tau}\left[p_{s}-c\left(v_{s}\right)\right] x_{s}=\delta\left[p_{\tau}-c\left(v_{\tau}\right)\right] x_{\tau}+\delta V_{\tau+1}$. First, we derive the incentive constraint that prevents the firm from cheating (only) in period $t$. If the firm follows its equilibrium strategy, $V_{t}=\delta\left[p_{t}-c\left(v_{t}\right)\right] x_{t}+\delta V_{t+1}$. If it cheats in period $t$, but not thereafter its expected payoff from period $t$ onwards is $\delta\left[p_{t}-c(0)\right] x_{t}+(1-\varphi) \delta V_{t+1}$. For the firm not to cheat in period $t$, it must hold that $\delta\left[p_{t}-c\left(v_{t}\right)\right] x_{t}+\delta V_{t+1} \geq \delta\left[p_{t}-c(0)\right] x_{t}+(1-\varphi) \delta V_{t+1}$, and thus $\varphi \delta V_{t+1} \geq \delta\left[c\left(v_{t}\right)-c(0)\right] x_{t}=\delta \gamma v_{t} x_{t}$ or $V_{t+1} \geq \frac{1}{\varphi} \gamma v_{t} x_{t}>0$, where positivity follows from $v_{t}>0$ and $x_{t}>0$. By assumption, $R(v, s)-\hat{p}(v)<\max [R(0, s)-c(0), 0]$ for all $v \in(0,1]$ and all $s \in S$. Hence there exists a positive function $\kappa:(0,1] \rightarrow \mathbb{R}_{++}$such that $\max [R(0, s)-c(0), 0]-[R(v, s)-\hat{p}(v)]>\kappa(v)>0$ for all $v \in(0,1]$ and all $s \in S$. Therefore, since $v_{t}>0$ and $x_{t}>0, p_{t}<\hat{p}\left(v_{t}\right)-\kappa\left(v_{t}\right)=c\left(v_{t}\right)+\frac{\rho}{\varphi} \gamma v_{t}-\kappa\left(v_{t}\right)$ because for $p_{t} \geq \hat{p}\left(v_{t}\right)-\kappa\left(v_{t}\right)$ and $v_{t}>0$ sales $x_{t}$ are zero. Thus, $p_{t}-c\left(v_{t}\right)<\frac{\rho}{\varphi} \gamma v_{t}-\kappa\left(v_{t}\right)$. Because of this and $\frac{1}{\varphi} \gamma v_{t} x_{t} \leq V_{t+1}, V_{t}=\delta\left[p_{t}-c\left(v_{t}\right)\right] x_{t}+\delta V_{t+1}<\delta \frac{\rho}{\varphi} \gamma v_{t} x_{t}-\delta \kappa\left(v_{t}\right) x_{t}+\delta V_{t+1} \leq \rho \delta V_{t+1}+$ $\delta V_{t+1}-\delta \kappa\left(v_{t}\right) x_{t}=V_{t+1}-\delta \kappa\left(v_{t}\right) x_{t}$, i.e., $V_{t+1}-V_{t}>\delta \kappa\left(v_{t}\right) x_{t}>0$. The preceding argument can be applied to any period $\tau$. Consequently, whenever $v_{\tau} x_{\tau}>0$ (which is equivalent to $v_{\tau}>0$ and $\left.x_{\tau}>0\right)$ for some $\tau, V_{\tau+1}-V_{\tau}>\delta \kappa\left(v_{\tau}\right) x_{\tau}>0$. Consider next the case where $v_{\tau} x_{\tau}=0$, i.e., where $v_{\tau}=0$ or $x_{\tau}=0$, or both. Notice that if $v_{\tau}=0$ and $x_{\tau}>0$, then $p_{\tau}=c(0)$ and thus $p_{\tau}-c\left(v_{\tau}\right)=0$. From $V_{\tau}=\delta\left[p_{\tau}-c\left(v_{\tau}\right)\right] x_{\tau}+\delta V_{\tau+1}$ and $\frac{1}{\delta}=1+\rho$ we get $V_{\tau+1}=(1+\rho) V_{\tau}-\left[p_{\tau}-c\left(v_{\tau}\right)\right] x_{\tau}$. Therefore, $v_{\tau} x_{\tau}=0$ implies $V_{\tau+1}-V_{\tau}=\rho V_{\tau}$. We know that $V_{t+1}>0$. If $v_{t+1} x_{t+1}=0$, the previous argument gives $V_{t+2}>V_{t+1}$. Moreover, we have shown that $v_{\tau} x_{\tau}>0$ for any $\tau$ implies $V_{\tau+1}-V_{\tau}>\delta \kappa\left(v_{\tau}\right) x_{\tau}>0$, hence $v_{t+1} x_{t+1}>0$ implies $V_{t+2}-V_{t+1}>\delta \kappa\left(v_{t+1}\right) x_{t+1}>0$. It follows that $V_{t+2}>V_{t+1}$ regardless of $v_{t+1}$ and $x_{t+1}$. Repeating this argument shows that $V_{\tau+1}>V_{\tau}$ for all $\tau \in\{t, t+1, \ldots\}$. 
By assumption, total expenditures $p_{\tau} x_{\tau}$ are uniformly bounded. Consequently, per period profits $\left[p_{\tau}-c\left(v_{\tau}\right)\right] x_{\tau} \leq p_{\tau} x_{\tau}$ are bounded by some number $M$ and thus $V_{\tau}, \tau \in\{t, t+1, \ldots\}$, is bounded by $M / \rho$. Therefore, the (increasing) sequence $\left\{V_{\tau}\right\}_{t}^{\infty}$ must converge to some $\bar{V}$. Together with $V_{t+1}>0$ this implies that there exists a sufficiently large $T>t$ such that for all $\tau \in\{T, T+1, \ldots\}$ it holds that $\frac{\rho}{2} V_{t+1}>V_{\tau+1}-V_{\tau}$ and thus $\frac{\rho}{2} V_{t+1}>V_{\tau+1}-V_{\tau}=\rho V_{\tau}-$ $\left[p_{\tau}-c\left(v_{\tau}\right)\right] x_{\tau} \geq \rho V_{t+1}-\left[p_{\tau}-c\left(v_{\tau}\right)\right] x_{\tau}$, which gives $\left[p_{\tau}-c\left(v_{\tau}\right)\right] x_{\tau}>\frac{\rho}{2} V_{t+1}>0$ (in addition, $p_{\tau}-c\left(v_{\tau}\right)>0$ follows). Since $p_{\tau}-c\left(v_{\tau}\right)<\hat{p}\left(v_{\tau}\right)-c\left(v_{\tau}\right)=\frac{\rho}{\varphi} \gamma v_{\tau} \leq \frac{\rho}{\varphi} \gamma, x_{\tau}>\frac{\varphi}{2 \gamma} V_{t+1}>0$. Moreover, $\left[p_{\tau}-c\left(v_{\tau}\right)\right] x_{\tau}>0$ implies $p_{\tau}>c(0)>0$ and thus, because expenditures $p_{\tau} x_{\tau}$ are uniformly bounded, $x_{\tau}<\bar{x}$ for some $\bar{x}$. Together with $\left[p_{\tau}-c\left(v_{\tau}\right)\right] x_{\tau}>\frac{\rho}{2} V_{t+1}$ this gives $p_{\tau}-c\left(v_{\tau}\right)>\frac{\rho}{2 x_{\tau}} V_{t+1}>\frac{\rho}{2 \bar{x}} V_{t+1}>0$. In addition, $0<p_{\tau}-c\left(v_{\tau}\right)<\hat{p}\left(v_{\tau}\right)-c\left(v_{\tau}\right)=\frac{\rho}{\varphi} \gamma v_{\tau}$ implies $\left[p_{\tau}-c\left(v_{\tau}\right)\right] \rightarrow 0$ for $v_{\tau} \rightarrow 0$. Therefore, there exists a $\bar{v}>0$ such that $v_{\tau}>\bar{v}$ for all $\tau \in\{T, T+1, \ldots\}$. Since $v_{\tau}>\bar{v}>0$ for all $\tau \in\{T, T+1, \ldots\}, \kappa\left(v_{\tau}\right)>\bar{\kappa}$ for some $\bar{\kappa}>0$ for all $\tau \in\{T, T+1, \ldots\}$. Finally, $v_{\tau} x_{\tau}>0$ implies $V_{\tau+1}-V_{\tau}>\delta \kappa\left(v_{\tau}\right) x_{\tau}>\delta \bar{\kappa} \frac{\varphi}{2 \gamma} V_{t+1}>0$ for all $\tau \in\{T, T+1, \ldots\}$, and thus the sequence $\left\{V_{\tau}\right\}_{t}^{\infty}$ cannot converge to some $\bar{V}$. This contradiction proves the proposition.

Proof of Lemma 1: Since the respective strategy profile is a Nash equilibrium of the restricted game, the incentive constraints for always actually producing the announced quality are satisfied. Otherwise customers would not buy the respective firm's product for a price above $c(0)$, the firm's profit would be zero and it would not have entered the market (since it has a positive entry cost). In addition, since all competitors' actions are constant in time, each firm's (constant) choice of quality and price maximizes in each individual period its per period profit, given all other incumbents' qualities and prices. Consequently, no incumbent can improve her payoff by deviating to a different (stationary or non-stationary) strategy with respect to quality and price. Moreover, each incumbent makes in each period a constant positive profit that must exceed the entry cost times the discount rate $\rho$ (otherwise the respective firm would not have entered the market). Therefore, it is optimal for each incumbent to enter in the first period and never to exit.

Proof of Proposition 2: The proof is by contradiction. Consider some firm that in a stationary equilibrium offers quality $\bar{v} \in(0,1)$ for the price $p(\bar{v})>\hat{p}(\bar{v})$. Assume the firm increases quality $\bar{v}$ to $\bar{v}+\varepsilon>\bar{v}$. Since $R_{v}\left(\bar{v}, s_{\min }\right)>\gamma$, there exists a price $p(\bar{v}+\varepsilon)$ such that $p(\bar{v})+\varepsilon R_{v}\left(\bar{v}, s_{\text {min }}\right)>p(\bar{v}+\varepsilon)>p(\bar{v})+\varepsilon \gamma$. In addition, $p(\bar{v})>\hat{p}(\bar{v})$ implies that 
for a sufficiently small $\varepsilon>0$ the inequality $p(\bar{v}+\varepsilon) \geq \hat{p}(\bar{v})+\frac{\rho \gamma}{\varphi} \varepsilon=\hat{p}(\bar{v}+\varepsilon)$ is satisfied. Moreover, if $\varepsilon>0$ is sufficiently small, it holds for each customer of the respective firm that $R(\bar{v}+\varepsilon, s)-R(\bar{v}, s) \geq \varepsilon R_{v}\left(\bar{v}, s_{\min }\right) \geq p(\bar{v}+\varepsilon)-p(\bar{v})$ because $R_{v s}(\cdot, \cdot)>0$ for all $v>0$, and thus $R(\bar{v}+\varepsilon, s)-p(\bar{v}+\varepsilon) \geq R(\bar{v}, s)-p(\bar{v})$. Therefore, under the alternative strategy of announcing and producing quality $\bar{v}+\varepsilon$ and charging the price $p(\bar{v}+\varepsilon)<$ $p(\bar{v})+\varepsilon R_{v}\left(\bar{v}, s_{\min }\right)$ the firm has at least as many customers as under the original strategy of selling quality $\bar{v}$ for the price $p(\bar{v})$. In addition, since $p(\bar{v}+\varepsilon)>p(\bar{v})+\varepsilon \gamma$ and thus $p(\bar{v}+\varepsilon)-c(\bar{v}+\varepsilon)>p(\bar{v})+\varepsilon \gamma-c(\bar{v})-\gamma \varepsilon=p(\bar{v})-c(\bar{v})$, the firm's profit per customer will increase. Consequently, the firm's payoff will increase, and hence the strategy to offer quality $\bar{v} \in(0,1)$ for the price $p(\bar{v})>\hat{p}(\bar{v})$ cannot optimal. This contradicts the assumption that it is an equilibrium strategy. If $R_{v}(v, s)>\gamma$ for all $v \in(0,1)$ and all $s \in S$, then the same argument shows that it cannot be optimal to offer any quality $v \in(0,1)$ for a price $p(v)>\hat{p}(v)$. Finally, $p(0)=c(0)=\hat{p}(0)$ holds trivially.

Proof of Proposition 3: First, we show by contradiction that if there is only one brand name, it will offer maximum quality $v=1$. Clearly, in a stationary equilibrium the respective single brand name will not offer minimum quality $v=0$ since profits would be zero and the entry cost could not be covered. Assume the respective brand name offers some quality level $\bar{v} \in(0,1)$ for some price $p(\bar{v}) \geq \hat{p}(\bar{v})=c(0)+\alpha \gamma \bar{v}$. For any customer $s$ of the brand name it must hold that she prefers $v=\bar{v}$ for the price $p(\bar{v})$ to (i) $v=0$ for the price $p(0)=c(0)$ and (ii) to not buying at all, i.e., it must hold that $R(\bar{v}, s)-p(\bar{v}) \geq \max [R(0, s)-c(0)$, 0$]$. If $R(\bar{v}, s)-p(\bar{v}) \geq R(0, s)-c(0) \geq 0$, then $R(\bar{v}, s)-R(0, s) \geq p(\bar{v})-c(0) \geq \hat{p}(\bar{v})-c(0)=$ $\alpha \gamma \bar{v}$. Moreover, if for some $s \in S, R(\bar{v}, s)-R(0, s) \geq \alpha \gamma \bar{v}$ for some $\bar{v} \in(0,1)$, then $R(1, s)-R(\bar{v}, s) \geq(1-\bar{v}) \alpha \gamma$, because from $R_{v v}(\cdot, s) \geq 0$ it follows that $\frac{R(1, s)-R(\bar{v}, s)}{1-\bar{v}} \geq$ $\frac{R(\bar{v}, s)-R(0, s)}{\bar{v}}$. Thus, $R(\bar{v}, s)-p(\bar{v}) \geq R(0, s)-c(0)$ implies $R(1, s)-[p(\bar{v})+(1-\bar{v}) \alpha \gamma] \geq$ $R(\bar{v}, s)-p(\bar{v})$. In addition, if $R(\bar{v}, s)-p(\bar{v}) \geq 0>R(0, s)-c(0)$, then $R(\bar{v}, s)-R(0, s)>$ $p(\bar{v})-c(0) \geq \hat{p}(\bar{v})-c(0)=\alpha \gamma \bar{v}$ and thus $R(1, s)-[p(\bar{v})+(1-\bar{v}) \alpha \gamma]>R(\bar{v}, s)-p(\bar{v})$ because $\frac{R(1, s)-R(\bar{v}, s)}{1-\bar{v}} \geq \frac{R(\bar{v}, s)-R(0, s)}{\bar{v}}>\alpha \gamma$ gives $R(1, s)>R(\bar{v}, s)+(1-\bar{v}) \alpha \gamma$. Consequently, $R(\bar{v}, s)-p(\bar{v}) \geq \max [R(0, s)-c(0), 0]$ always implies $R(1, s)-[p(\bar{v})+(1-\bar{v}) \alpha \gamma] \geq$ $R(\bar{v}, s)-p(\bar{v})$. Because of this, the respective brand name will not lose demand, if it offers quality $v=1$ for the price $p(1)=p(\bar{v})+(1-\bar{v}) \alpha \gamma$ instead of quality $\bar{v} \in(0,1)$ for the price $p(\bar{v})$. In addition, its profit per customer will increase from $(\alpha-1) \gamma \bar{v}$ to $(\alpha-1) \gamma$. It follows that if there is only one brand name, it will offer maximum quality $v=1$. 
Consider now the case of at least two brand names. By the same argument as before, at least one firm offers quality $v=1$. If two or more firms offer quality $v=1, p(1)=\hat{p}(1)$ because of Bertrand competition. In this case, any third firm that offers some quality $\bar{v} \in(0,1)$ for some price $p(\bar{v}) \geq \hat{p}(\bar{v})$ will attract customer type $s$ only if $R(\bar{v}, s)-p(\bar{v}) \geq$ $\max [R(1, s)-\hat{p}(1), R(0, s)-c(0), 0]$. However, we have already shown that $R(\bar{v}, s)-$ $p(\bar{v}) \geq \max [R(0, s)-c(0), 0]$ implies $R(\bar{v}, s)-p(\bar{v}) \leq R(1, s)-[p(\bar{v})+(1-\bar{v}) \alpha \gamma] \leq$ $R(1, s)-[\hat{p}(\bar{v})+(1-\bar{v}) \alpha \gamma]=R(1, s)-\hat{p}(1)$. That is, whenever some type $s$ prefers $v=\bar{v}$ for the price $p(\bar{v})$ to $v=0$ for the price $p(0)=c(0)$ and to not buying at all, that type prefers, at least weakly, $v=1$ for the price $\hat{p}(1)$ to $v=\bar{v}$ for the price $p(\bar{v})$. Consequently, any firm that offers some quality $\bar{v} \in(0,1)$ for some price $p(\bar{v}) \geq \hat{p}(\bar{v})$ has demand of measure zero, and thus zero profits, and cannot cover its entry cost. Hence whenever at least two firms offer $v=1$ no intermediate quality $v \in(0,1)$ will be available in the market. The same conclusion follows if only one firm offers $v=1$ for the price $p(1)=\hat{p}(1)$. The remaining case is the one where $v=1$ is being offered for some price $p(1)>\hat{p}(1)$ by a single firm and at least one other firm offers $\bar{v} \in(0,1)$ for some price $p(\bar{v}) \geq \hat{p}(\bar{v})$. We have already shown that $R(\bar{v}, s)-p(\bar{v}) \geq \max [R(0, s)-c(0), 0]$ implies $R(1, s)-$ $[p(\bar{v})+(1-\bar{v}) \alpha \gamma] \geq R(\bar{v}, s)-p(\bar{v})$. Therefore, the firm offering $v=\bar{v}$ can have customers only if $p(1) \geq p(\bar{v})+(1-\bar{v}) \alpha \gamma$ since otherwise $R(\bar{v}, s)-p(\bar{v}) \geq \max [R(0, s)-c(0), 0]$ implies $R(\bar{v}, s)-p(\bar{v}) \leq R(1, s)-[p(\bar{v})+(1-\bar{v}) \alpha \gamma]<R(1, s)-p(1)$, i.e., rather than buying $v=\bar{v}$ for the price $p(\bar{v})$ each type $s \in S$ prefers either not to buy at all, to buy $v=0$ or to buy $v=1$. If equality $p(1)=p(\bar{v})+(1-\bar{v}) \alpha \gamma$ holds, the set of customers is of measure zero, thus positive profits of the firm offering $v=\bar{v}$ imply $p(1)>p(\bar{v})+(1-\bar{v}) \alpha \gamma$. If the respective firm offers instead $v=1$ for the price $\tilde{p}(1)=p(\bar{v})+(1-\bar{v}) \alpha \gamma<p(1)$, it will not lose any customers (because, as shown, $R(1, s)-\tilde{p}(1) \geq R(\bar{v}, s)-p(\bar{v})$ for each customer $s$ ) and take all customers from the rival firm that offers $v=1$ for some price $p(1)>\tilde{p}(1)$. In addition, its profit per customer and hence its payoff increases. Thus, also in this last case it cannot be an equilibrium that some firm offers some intermediate quality $\bar{v} \in(0,1)$. Consequently, there is no case where a brand name offers an intermediate quality $v \in(0,1)$. In contrast, it is an equilibrium that all brand names offer quality $v=1$ for the price $\hat{p}(1)$, provided the market can accommodate at least two firms (i.e., if two firms offer quality $v=1$ for the price $\hat{p}(1)$, each firm's discounted stream of profits covers the entry cost). If the market accommodates at least one firm (i.e., if for a single firm that 
offers quality $v=1$ for the profit-maximizing price $p(1) \geq \hat{p}(1)$ the discounted stream of profits covers the entry cost), quality $v=1$ will be available in the market for some price $p(1) \geq \hat{p}(1)$. For the proof of the second part of the proposition, which assumes $R_{s}(1, \cdot)>0$, consider first the case where quality $v=1$ is available for some price $p(1) \geq \hat{p}(1)$ and is demanded by some but not all customers, i.e., $R\left(1, s_{\max }\right)-p(1) \geq \max \left[R\left(0, s_{\max }\right)-c(0), 0\right]$ and $R\left(1, s_{\min }\right)-p(1) \leq \max \left[R\left(0, s_{\min }\right)-c(0), 0\right]$. Then there exists a unique type $\bar{s} \in S$ such that $R(1, \bar{s})-p(1)=\max [R(0, \bar{s})-c(0), 0]$. Uniqueness follows because $R(1, \cdot)$ and $s=R(1, \cdot)-R(0, \cdot)$ are both strictly increasing in $s$ and because of the following contradiction: if $R(1, \bar{s})-p(1)=R(0, \bar{s})-c(0)>0$ and $R\left(1, \bar{s}^{\prime}\right)-p(1)=0>R\left(0, \bar{s}^{\prime}\right)-c(0)$ for some $\bar{s} \in S$ and $\bar{s}^{\prime} \in S$, then $R(1, \bar{s})-p(1)>0=R\left(1, \bar{s}^{\prime}\right)-p(1)$ implies $\bar{s}>\bar{s}^{\prime}$ because $R_{s}(1, \cdot)>0$, whereas $R(1, \bar{s})-p(1)=R(0, \bar{s})-c(0)$ and $R\left(1, \bar{s}^{\prime}\right)-p(1)>R\left(0, \bar{s}^{\prime}\right)-c(0)$ imply $\bar{s}=R(1, \bar{s})-R(0, \bar{s})=p(1)-c(0)<R\left(1, \bar{s}^{\prime}\right)-R\left(0, \bar{s}^{\prime}\right)=\bar{s}^{\prime}$ and thus $\bar{s}^{\prime}>\bar{s}$. Moreover, because $R(1, \cdot)$ and $s=R(1, \cdot)-R(0, \cdot)$ are both strictly increasing in $s$, all types $s \in\left[s_{\min }, \bar{s}\right)$ either consume quality $v=0$ or abstain from consuming the good, and all types $s \in\left(\bar{s}, s_{\max }\right]$ consume quality $v=1$. Since $R(1, s)-\hat{p}(1)=R(1, s)-c(0)-\alpha \gamma$ decreases strictly with $\alpha$, the solution $\bar{s}$ of $R(1, \bar{s})-\hat{p}(1)=\max [R(0, \bar{s})-c(0), 0]$ must also strictly decrease with $\alpha$ for $\bar{s} \in\left(s_{\min }, s_{\max }\right)$. Finally, if all types $s \in\left[s_{\min }, s_{\max }\right]$ demand $v=1, \bar{s}=s_{\min } ;$ and if no type $s \in\left[s_{\min }, s_{\max }\right]$ demands $v=1, \bar{s}=s_{\max }$.

Proof of Proposition 4: First we show that at the price $p(1)=\hat{p}(1)$ demand for quality $v=1$ is bounded from below by $1-F\left(s_{1}\right)$, regardless of the availability of other quality levels. Since $R_{v}(1, s)$ and $R(1, s)$ are both strictly increasing in $s$, the definition of $s_{1}$ implies that for all $s>s_{1}$ it holds that $R_{v}(1, s)>\alpha \gamma$ and $R(1, s)>\hat{p}(1)$. Since $R_{v v}(v, s) \leq 0$ and $R_{v}(1, s)>\alpha \gamma$ imply $R(1, s)-R(v, s)=\int_{v}^{1} R_{v}(w, s) d w>\int_{v}^{1} \alpha \gamma d w=(1-v) \alpha \gamma=$ $\hat{p}(1)-\hat{p}(v)$, it holds that $R(1, s)-\hat{p}(1)>R(v, s)-\hat{p}(v)$. Therefore, at the price $\hat{p}(1)$ every type $s>s_{1}$ strictly prefers quality $v=1$ to buying any other quality $v<1$ for a price $p(v) \geq \hat{p}(v)$. Moreover, $R(1, s)>\hat{p}(1)$ implies that type $s$ strictly prefers to buy quality $v=1$ for the price $\hat{p}(1)$ to not buying. Consequently, at the price $p(1)=\hat{p}(1)$ every type $s>s_{1}$ demands one unit of quality $v=1$ and thus total demand for quality $v=1$ is at least $1-F\left(s_{1}\right)$. If $n \geq 1$ brand names offer $v=1$ for the price $\hat{p}(1)$ each has a profit per period of at least $\frac{1}{n}\left[1-F\left(s_{1}\right)\right][\hat{p}(1)-c(1)]=\frac{1}{n}\left[1-F\left(s_{1}\right)\right](\alpha-1) \gamma$. If $n \geq 2$ brand names offer quality $v=1$, Bertrand competition implies that all charge the price $p(1)=\hat{p}(1)$. For all intermediate qualities $v \in(0,1)$ the price is $p(v)=\hat{p}(v)$ because of 
Proposition 2 and $R_{v}(\cdot, \cdot)>\gamma$ for $v>0$. Therefore, the profit per customer that a firm offering $v<1$ achieves is $(\alpha-1) \gamma v<(\alpha-1) \gamma$ (hence no brand name will offer $v=0$ ). Moreover, if some brand name offers quality $v=1$ for the price $p(1)=\hat{p}(1)$, total demand for all intermediate quality levels $v \in(0,1)$ is bounded from above by $F\left(s_{1}\right)-F\left(s_{0}\right)$. In this case, if $k \geq 1$ brand names offer (identical or different) intermediate quality levels $v \in(0,1)$, the lowest profit per period must be less than $\frac{1}{k}\left[F\left(s_{1}\right)-F\left(s_{0}\right)\right](\alpha-1) \gamma$, because $\frac{1}{k}\left[F\left(s_{1}\right)-F\left(s_{0}\right)\right](\alpha-1) \gamma$ exceeds the average profit of those $k$ firms. A necessary condition for a stationary equilibrium where $k$ firms offer some intermediate quality levels and $n$ firms offer quality $v=1$, is that no firm can increase its payoff, if it switches to some other quality. This implies, in particular, that a brand name with the lowest profit per period among the $k \geq 1$ brand names that offer intermediate quality levels must not be able to increase its profit per period if it switches to quality $v=1$. Denote by $\pi$ the lowest profit per period that a brand name that has chosen some intermediate quality $v \in(0,1)$ achieves, and by $\psi$ the one that this brand name achieves instead if it switches to quality $v=1$. If $k \geq 1$ firms offer some intermediate quality levels $v \in(0,1)$ and either $n \geq 2$ firms offer quality $v=1$, which implies $p(1)=\hat{p}(1)$, or $n=1$ firm offers quality $v=1$ for the price $p(1)=\hat{p}(1)$, the equilibrium condition $\pi \geq \psi$, together with the previous arguments, implies $\frac{1}{k}\left[F\left(s_{1}\right)-F\left(s_{0}\right)\right](\alpha-1) \gamma>\pi \geq \psi \geq \frac{1}{n+1}\left[1-F\left(s_{1}\right)\right](\alpha-1) \gamma$, and thus $\frac{\lambda}{1-\lambda}=\frac{1-F\left(s_{1}\right)}{F\left(s_{1}\right)-F\left(s_{0}\right)}<\frac{n+1}{k}$. Because $n+k=N$, this gives $n>\lambda(N+1)-1$ whenever $n \leq N-1$ (the condition $k \geq 1$ excludes $n=N)$ and $p(1)=\hat{p}(1)$.

Consider now the case where all $N$ brand names in the market offer some intermediate quality levels $v \in(0,1)$. In this case the average (and thus the minimal) profit per period is strictly less than $\frac{1}{N}\left[1-F\left(s_{0}\right)\right](\alpha-1) \gamma$. Since a brand name can always offer quality $v=1$ for the price $p(1)=\hat{p}(1)$ and receive a profit per period of at least $\left[1-F\left(s_{1}\right)\right](\alpha-1) \gamma$, it must hold that $\left[1-F\left(s_{1}\right)\right]<\frac{1}{N}\left[1-F\left(s_{0}\right)\right]$ and thus $\lambda N<1$. Consequently, the proposition's assumption $N \geq \frac{1}{\lambda}+1$ implies that at least one firm offers maximum quality $v=1$. Consider now the case where out of $N$ brand names in the market $N-1$ offer some intermediate quality levels $v \in(0,1)$ and one offers maximum quality $v=1$. We have to distinguish the subcase where the firm that offers $v=1$ charges a price $p(1)=\hat{p}(1)$ from the subcase where it charges a price $p(1)>\hat{p}(1)$. The subcase $p(1)=\hat{p}(1)$ has already been dealt with above: $k=N-1$ firms offer some intermediate quality levels and $n=1$ firm offers quality $v=1$ for the price $p(1)=\hat{p}(1)$. We concluded that $n>\lambda(N+1)-1$. Since $n=1$, 
$N<\frac{2}{\lambda}-1$. Consider now the subcase $p(1)>\hat{p}(1)$. In this subcase the average (and thus the minimal) profit per period of the $N-1$ firms is strictly less than $\frac{1}{N-1}\left[1-F\left(s_{0}\right)\right](\alpha-1) \gamma$. If a brand name switches from intermediate quality to maximum quality and charges the price $\hat{p}(1)$, it gets all the customers buying $v=1$ and thus receives a profit per period of at least $\left[1-F\left(s_{1}\right)\right](\alpha-1) \gamma$. Since this must not increase the respective firm's payoff, $\left[1-F\left(s_{1}\right)\right]<\frac{1}{N-1}\left[1-F\left(s_{0}\right)\right]$, or $(N-1) \lambda<1$. Thus, $N<\frac{1}{\lambda}+1$. Hence the proposition's assumption $N \geq \frac{1}{\lambda}+1$ implies that at least two brand names must offer maximum quality $v=1$. From of the analysis above it follows that $n>\lambda(N+1)-1$ whenever $n \leq N-1$. For $n=N$ the inequality is also satisfied, provided $\lambda<1$. If $\lambda=1$ (and $N \geq 2$ ), $n=N$ follows because every $n \leq N-1$ violates $n>\lambda(N+1)-1=N$. Hence for every possible case that is compatible with $N \geq \frac{1}{\lambda}+1$ it must hold (i) that $n>\lambda(N+1)-1$ if $\lambda<1$ and $n=N$ if $\lambda=1$, and (ii) that $p(1)=\hat{p}(1)$.

Finally, assume $N \in\left[3, \frac{\lambda}{1-\lambda}\right]$. This implies $\frac{\lambda}{1-\lambda} \geq 3$ and thus $\lambda \geq \frac{3}{4}$. First we show that at least one brand name offers quality $v=1$. If no brand name offers quality $v=1$, brand names' average profit per period is below $\frac{1}{N}\left[1-F\left(s_{0}\right)\right](\alpha-1) \gamma \leq \frac{1}{3}\left[1-F\left(s_{0}\right)\right](\alpha-1) \gamma=$ $\frac{1}{3} \frac{1-F\left(s_{1}\right)}{\lambda}(\alpha-1) \gamma \leq \frac{4}{9}\left[1-F\left(s_{1}\right)\right](\alpha-1) \gamma<\left[1-F\left(s_{1}\right)\right](\alpha-1) \gamma$ because $N \geq 3$ and $\lambda \geq \frac{3}{4}$. Thus, at least one brand name can do better by offering $v=1$ for the price $p(1)=\hat{p}(1)$. Hence in a stationary equilibrium at least $n \geq 1$ brand names offer $v=1$. If $n \geq 2, p(1)=\hat{p}(1)$ follows because of Bertrand competition. If $p(1)=\hat{p}(1)$, total demand for intermediate quality levels is bounded by $F\left(s_{1}\right)-F\left(s_{0}\right)$. Thus, if $p(1)=\hat{p}(1)$ and $k \in$ $[1, N-1]$ firms offer intermediate quality levels, their average profit per period is bounded by $\frac{1}{k}\left[F\left(s_{1}\right)-F\left(s_{0}\right)\right](\alpha-1) \gamma \leq \frac{1}{N}\left[1-F\left(s_{1}\right)\right](\alpha-1) \gamma \leq \frac{1}{N-k+1}\left[1-F\left(s_{1}\right)\right](\alpha-1) \gamma$, where the first inequality holds because $N \leq \frac{\lambda}{1-\lambda}=\frac{1-F\left(s_{1}\right)}{F\left(s_{1}\right)-F\left(s_{0}\right)}$ gives $F\left(s_{1}\right)-F\left(s_{0}\right) \leq \frac{1}{N}\left[1-F\left(s_{1}\right)\right]$. Consequently, a firm with the minimum profit among the $k \in[1, N-1]$ firms offering intermediate quality levels can increase its payoff, if it offers $v=1$ for the price $p(1)=\hat{p}(1)$. Therefore, whenever a brand name offers $v=1$ for the price $p(1)=\hat{p}(1)$, this must hold for all $N$ brand names in the market. Proposition 4 follows, if we can exclude that $n=1$ brand name offers $v=1$ for some price $p(1)>\hat{p}(1)$ and the $k=N-1$ remaining brand names all offer intermediate quality levels. Because $N \geq 3$ and, since $\lambda \geq \frac{3}{4}, 1-F\left(s_{0}\right)=\frac{1}{\lambda}\left[1-F\left(s_{1}\right)\right] \leq$ $\frac{4}{3}\left[1-F\left(s_{1}\right)\right]$, the average profit per period of the latter $k=N-1$ remaining brand names is bounded by $\frac{1}{N-1}\left[1-F\left(s_{0}\right)\right](\alpha-1) \gamma \leq \frac{1}{2} \frac{4}{3}\left[1-F\left(s_{1}\right)\right](\alpha-1) \gamma<\left[1-F\left(s_{1}\right)\right](\alpha-1) \gamma$. Since $p(1)>\hat{p}(1)$, a brand name that switches from $v \in(0,1)$ to $v=1$ and charges the price 
$\hat{p}(1)$ gets all the demand for $v=1$, which is at least $1-F\left(s_{1}\right)$, and thus achieves a profit per period of at least $\left[1-F\left(s_{1}\right)\right](\alpha-1) \gamma$. The previous inequality shows that this is more than a brand name with the minimal profit per period among those offering intermediate quality levels achieves. Hence it cannot be a stationary equilibrium that $n=1$ brand name offers $v=1$ for the price $p(1)>\hat{p}(1)$ and the $k=N-1$ remaining brand names all offer intermediate quality levels. Thus, for $N \in\left[3, \frac{\lambda}{1-\lambda}\right]$ we have excluded all cases where some brand name offers some intermediate quality level as an outcome of a stationary equilibrium. Since $N \geq 3, p(1)=\hat{p}(1)$ follows.

Proof of Proposition 5: First we show that it is an equilibrium that there are $N \geq 2$ brand names in the market, all of which offer quality $v=1$. Recall that $R_{v}(\cdot, \cdot)>\gamma$ for all $v \in(0,1)$ implies $p(v)=\hat{p}(v)$ for all $v \in(0,1)$ and a profit per customer of $(\alpha-1) \gamma v$. Since $N \geq 2$, Bertrand competition implies $p(1)=\hat{p}(1)$. Aggregate demand for quality $v=1$ is $1-F(\bar{s})$ and each brand name in the market has a profit per period of $\frac{1}{N}[1-F(\bar{s})](\alpha-1) \gamma$. Since $\eta \rho \leq \frac{1}{N}[1-F(\bar{s})](\alpha-1) \gamma$, each brand name in the market has a non-negative payoff $\frac{1}{\rho N}[1-F(\bar{s})](\alpha-1) \gamma-\eta \geq 0$ and thus is at least not worse off than if it stayed out of the market. Consider a brand name that has the strategy not to enter the market, but deviates and enters. The profit per period it gets is $\frac{1}{N+1}[1-F(\bar{s})](\alpha-1) \gamma$, if it offers quality $v=1$, and is less than $\left[F\left(s_{1}\right)-F\left(s_{0}\right)\right](\alpha-1) \gamma$, if it offers some intermediate quality $v \in(0,1)$. The inequalities $\frac{1}{N+1}[1-F(\bar{s})](\alpha-1) \gamma \leq \eta \rho$ and $\left[F\left(s_{1}\right)-F\left(s_{0}\right)\right](\alpha-1) \gamma \leq \eta \rho$ imply that the resulting payoff is non-positive in each case. Thus, the deviation does not increase the payoff. Finally, if a brand name in the market deviates to some quality $v \in[0,1)$, its profit per period is less than $\left[F\left(s_{1}\right)-F\left(s_{0}\right)\right](\alpha-1) \gamma$, and since $\left[F\left(s_{1}\right)-F\left(s_{0}\right)\right](\alpha-1) \gamma \leq$ $\eta \rho \leq \frac{1}{N}[1-F(\bar{s})](\alpha-1) \gamma$ the deviation decreases its payoff. This proves the first part of the proposition. Consider now the case where $N \geq 3$. As a first step we show that the proposition's inequalities imply $1-F\left(s_{0}\right)<\frac{N-1}{N-2}\left[1-F\left(s_{1}\right)\right]$. From concavity of $R(\cdot, \bar{s})$ in $v$ and the definition of $\bar{s}$ it follows that $R_{v}(0, \bar{s}) \geq R(1, \bar{s})-R(0, \bar{s}) \geq p(1)-c(0) \geq$ $\hat{p}(1)-c(0)=\alpha \gamma$ and thus $\bar{s} \geq s_{0}$, since the definition of $s_{0}$ (at the beginning of Section 7) implies $R_{v}(0, s)<\alpha \gamma$ for $s<s_{0}$. Because of $\eta>0$ and the proposition's first inequality, $-\frac{1}{N}[1-F(\bar{s})]<0 \leq F(\bar{s})-F\left(s_{0}\right)$ and thus $1-F\left(s_{0}\right)>\frac{N-1}{N}[1-F(\bar{s})]$. From this and the assumption $\left[F\left(s_{1}\right)-F\left(s_{0}\right)\right](\alpha-1) \gamma \leq \eta \rho \leq \frac{1}{N}[1-F(\bar{s})](\alpha-1) \gamma$, which implies $F\left(s_{1}\right)-F\left(s_{0}\right) \leq \frac{1}{N}[1-F(\bar{s})]$, it follows that $1-F\left(s_{0}\right) \leq 1-F\left(s_{1}\right)+\frac{1}{N}[1-F(\bar{s})]<$ $1-F\left(s_{1}\right)+\frac{1}{N-1}\left[1-F\left(s_{0}\right)\right]$ and hence $1-F\left(s_{0}\right)<\frac{N-1}{N-2}\left[1-F\left(s_{1}\right)\right]$. If $k \in[N-1, N]$ 
brand names offer intermediate quality levels, their average profit per period is less than $\frac{1}{k}\left[1-F\left(s_{0}\right)\right](\alpha-1) \gamma<\frac{N-1}{2(N-2)}\left[1-F\left(s_{1}\right)\right](\alpha-1) \gamma \leq\left[1-F\left(s_{1}\right)\right](\alpha-1) \gamma$ because $k \geq$ $N-1 \geq 2$ and $N \geq 3$. Whenever $n=N-k \leq 1$ firms offer maximum quality $v=1$ and $p(1)>\hat{p}(1)$ if $n=1$, a brand name that switches from intermediate to maximum quality and charges the price $\hat{p}(1)$ gets all the demand for $v=1$ and thus achieves a profit per period that is at least $\left[1-F\left(s_{1}\right)\right](\alpha-1) \gamma>\frac{1}{k}\left[1-F\left(s_{0}\right)\right](\alpha-1) \gamma$. Consequently, it cannot be a stationary equilibrium that $k \in[N-1, N]$ brand names offer intermediate quality levels and $p(1)>\hat{p}(1)$ if $k=N-1$. There remain two cases that we need to exclude: (i) $k \in[1, N-2]$ brand names offer intermediate quality levels, which implies that $n=N-k \geq 2$ brand names offer maximum quality and thus $p(1)=\hat{p}(1)$; (ii) $k=N-1$ brand names offer intermediate quality levels and the brand name that offers maximum quality charges the price $p(1)=\hat{p}(1)$. In both cases it holds that $p(1)=\hat{p}(1)$, and thus that the average profit per period of the firms that offer some intermediate quality $v \in(0,1)$ is less than $\frac{1}{k}\left[F\left(s_{1}\right)-F\left(s_{0}\right)\right](\alpha-1) \gamma \leq\left[F\left(s_{1}\right)-F\left(s_{0}\right)\right](\alpha-1) \gamma \leq \eta \rho$. Therefore, at least one brand name that offers intermediate quality cannot cover its entry cost and thus the constellation cannot be the outcome of a a stationary equilibrium. In addition, it holds even for the continuation game that takes place after entry among the $N$ brand names in the market, that in every equilibrium where equilibrium strategies are constant all $N$ brand names offer maximum quality. ${ }^{34}$ It follows that in every stationary equilibrium all $N$ brand names in the market must offer maximum quality $v=1$. The first part of the proposition

\footnotetext{
${ }^{34}$ Notice that we need to consider only the case where quality $v=1$ is available for the price $p(1)=\hat{p}(1)$. Hence whenever $k \geq 1$ brand names offer some intermediate quality levels, their average profit per period is less than $\frac{1}{k}\left[F\left(s_{1}\right)-F\left(s_{0}\right)\right](\alpha-1) \gamma$. From $\frac{N-1}{N-2}\left[1-F\left(s_{1}\right)\right]>1-F\left(s_{0}\right)=\left[1-F\left(s_{1}\right)\right]+\left[F\left(s_{1}\right)-F\left(s_{0}\right)\right]$ it follows that $F\left(s_{1}\right)-F\left(s_{0}\right)<\frac{1}{N-2}\left[1-F\left(s_{1}\right)\right]$. If $k \geq 2$ and one of the $k$ firms offering intermediate quality switches to maximum quality $v=1$, its resulting profit is at least $\frac{1}{N-k+1}\left[1-F\left(s_{1}\right)\right](\alpha-1) \gamma \geq$ $\frac{1}{(N-2) k}\left[1-F\left(s_{1}\right)\right](\alpha-1) \gamma>\frac{1}{k}\left[F\left(s_{1}\right)-F\left(s_{0}\right)\right](\alpha-1) \gamma$, where the first inequality follows because $N \geq 3$ and $k \geq 2$, which implies $(N-2) k-(N-k+1)=N k-k-N-1=(N-1)(k-1)-2 \geq 0$, and the second inequality follows from $F\left(s_{1}\right)-F\left(s_{0}\right)<\frac{1}{N-2}\left[1-F\left(s_{1}\right)\right]$. If $k=1$ brand name offers some intermediate quality, its profit per period is less than $\left[F\left(s_{1}\right)-F\left(s_{0}\right)\right](\alpha-1) \gamma$. If it switches to maximum quality $v=1$, the resulting profit per period is $\frac{1}{N}[1-F(\bar{s})](\alpha-1) \gamma$ because then all $N$ brand names offer maximum quality. Hence the propositions's assumption $\left[F\left(s_{1}\right)-F\left(s_{0}\right)\right](\alpha-1) \gamma \leq \eta \rho \leq \frac{1}{N}[1-F(\bar{s})](\alpha-1) \gamma$ implies that the respective brand name increases its payoff by switching to maximum quality. Therefore, in every equilibrium of the continuation game where equilibrium strategies are constant all brand names in the market offer maximum quality.
} 
implies that a respective stationary equilibrium does, in fact, exist.

\section{References}

Bagwell, K. (1990), "Informational Product Differentiation as a Barrier to Entry," International Journal of Industrial Organization 9, 207-223.

Bagwell K. and M. H. Riordan (1991), "High and Declining Prices Signal Product Quality," American Economic Review 81, 224-239.

Bester, H. (1998), "Quality Uncertainty Mitigates Product Differentiation," RAND Journal of Economics 29, 828-844.

Coyle, W. (2002), "Enhancing Food Safety in the APEC Region," Agricultural Outlook, December 2002, 28-32.

Gabszewicz, J. J. and I. Grilo (1992), "Price Competition When Consumers Are Uncertain About Which Firm Sells Which Quality," Journal of Economics 83 Mangement Strategy 1, 629-650.

Gabszewicz, J. J. and J.-F. Thisse (1979), "Price Competition, Quality and Income Disparities," Journal of Economic Theory 20, 340-359.

Gabszewicz, J. J. and J.-F. Thisse (1980), "Entry (and Exit) in a Differentiated Industry," Journal of Economic Theory 22, 327-338.

Gabszewicz, J. J. and X. Y. Wauthy (2002), "Quality Underprovision by a Monopolist When Quality Is Not Costly," Economics Letters 77, 65-72.

Gal-Or, E. (1983), "Quality and Quantity Competition," Bell Journal of Economics 14, 590-600.

Hellmann, T. F., K. C. Murdock, and J. E. Stiglitz (2000), "Liberalization, Moral Hazard in Banking, and Prudential Regulation: Are Capital Requirements Enough?" American Economic Review 90, 147-165. 
Klein, B. and K. B. Leffler (1981), "The Role of Market Forces in Assuring Contractual Performance," Journal of Political Economy 89, 615-641.

Mussa, M. and S. Rosen (1978), "Monopoly and Product Quality," Journal of Economic Theory 18, 301-317.

Nelson, P. (1970), "Information and Consumer Behavior," Journal of Political Economy 78, 311-329.

Repullo, R. (2002), "Capital Requirements, Market Power and Risk-Taking in Banking," CEMFI Working Paper No. 0208, November 2002.

Riordan, M. H. (1986), "Monopolistic Competition with Experience Goods," Quarterly Journal of Economics 101, 265-279.

Rogerson, W. P. (1988), "Price Advertising and the Deterioration of Product Quality," Review of Economic Studies 55, 215-229.

Shaked, A. and J. Sutton (1982), "Relaxing Price Competition Through Product Differemntiation," Review of Economic Studies 49, 3-13.

Shaked, A. and J. Sutton (1983), "Natural Oligopolies," Econometrica 51, 1469-1483.

Shapiro, C. (1983), "Premiums for High Quality Products as Returns to Reputation," Quarterly Journal of Economics 98, 659-679.

Schmalensee, R. (1982), "Product Differentiation Advantages of Pioneering Brands," American Economic Review 72, 349-365.

Wolinsky, A. (1983), "Prices as Signals of Product Quality," Review of Economic Studies 50, 647-658. 


\section{CESifo Working Paper Series}

(for full list see www.cesifo.de)

1209 Stephan Klasen and Thorsten Nestmann, Population, Population Density, and Technological Change, June 2004

1210 Wolfgang Ochel, Welfare Time Limits in the United States - Experiences with a New Welfare-to-Work Approach, June 2004

1211 Luis H. R. Alvarez and Erkki Koskela, Taxation and Rotation Age under Stochastic Forest Stand Value, June 2004

1212 Bernard M. S. van Praag, The Connexion Between Old and New Approaches to Financial Satisfaction, June 2004

1213 Hendrik Hakenes and Martin Peitz, Selling Reputation When Going out of Business, June 2004

1214 Heikki Oksanen, Public Pensions in the National Accounts and Public Finance Targets, June 2004

1215 Ernst Fehr, Alexander Klein, and Klaus M. Schmidt, Contracts, Fairness, and Incentives, June 2004

1216 Amihai Glazer, Vesa Kanniainen, and Panu Poutvaara, Initial Luck, Status-Seeking and Snowballs Lead to Corporate Success and Failure, June 2004

1217 Bum J. Kim and Harris Schlesinger, Adverse Selection in an Insurance Market with Government-Guaranteed Subsistence Levels, June 2004

1218 Armin Falk, Charitable Giving as a Gift Exchange - Evidence from a Field Experiment, June 2004

1219 Rainer Niemann, Asymmetric Taxation and Cross-Border Investment Decisions, June 2004

1220 Christian Holzner, Volker Meier, and Martin Werding, Time Limits on Welfare Use under Involuntary Unemployment, June 2004

1221 Michiel Evers, Ruud A. de Mooij, and Herman R. J. Vollebergh, Tax Competition under Minimum Rates: The Case of European Diesel Excises, June 2004

1222 S. Brock Blomberg and Gregory D. Hess, How Much Does Violence Tax Trade?, June 2004

1223 Josse Delfgaauw and Robert Dur, Incentives and Workers' Motivation in the Public Sector, June 2004 
1224 Paul De Grauwe and Cláudia Costa Storti, The Effects of Monetary Policy: A MetaAnalysis, June 2004

1225 Volker Grossmann, How to Promote R\&D-based Growth? Public Education Expenditure on Scientists and Engineers versus R\&D Subsidies, June 2004

1226 Bart Cockx and Jean Ries, The Exhaustion of Unemployment Benefits in Belgium. Does it Enhance the Probability of Employment?, June 2004

1227 Bertil Holmlund, Sickness Absence and Search Unemployment, June 2004

1228 Klaas J. Beniers and Robert Dur, Politicians' Motivation, Political Culture, and Electoral Competition, June 2004

1229 M. Hashem Pesaran, General Diagnostic Tests for Cross Section Dependence in Panels, July 2004

1230 Wladimir Raymond, Pierre Mohnen, Franz Palm, and Sybrand Schim van der Loeff, An Empirically-Based Taxonomy of Dutch Manufacturing: Innovation Policy Implications, July 2004

1231 Stefan Homburg, A New Approach to Optimal Commodity Taxation, July 2004

1232 Lorenzo Cappellari and Stephen P. Jenkins, Modelling Low Pay Transition Probabilities, Accounting for Panel Attrition, Non-Response, and Initial Conditions, July 2004

1233 Cheng Hsiao and M. Hashem Pesaran, Random Coefficient Panel Data Models, July 2004

1234 Frederick van der Ploeg, The Welfare State, Redistribution and the Economy, Reciprocal Altruism, Consumer Rivalry and Second Best, July 2004

1235 Thomas Fuchs and Ludger Woessmann, What Accounts for International Differences in Student Performance? A Re-Examination Using PISA Data, July 2004

1236 Pascalis Raimondos-Møller and Alan D. Woodland, Measuring Tax Efficiency: A Tax Optimality Index, July 2004

1237 M. Hashem Pesaran, Davide Pettenuzzo, and Allan Timmermann, Forecasting Time Series Subject to Multiple Structural Breaks, July 2004

1238 Panu Poutvaara and Andreas Wagener, The Invisible Hand Plays Dice: Eventualities in Religious Markets, July 2004

1239 Eckhard Janeba, Moral Federalism, July 2004

1240 Robert S. Chirinko, Steven M. Fazzari, and Andrew P. Meyer, That Elusive Elasticity: A Long-Panel Approach to Estimating the Capital-Labor Substitution Elasticity, July 2004 
1241 Hans Jarle Kind, Karen Helene Midelfart, Guttorm Schjelderup, Corporate Tax Systems, Multinational Enterprises, and Economic Integration, July 2004

1242 Vankatesh Bala and Ngo Van Long, International Trade and Cultural Diversity: A Model of Preference Selection, July 2004

1243 Wolfgang Eggert and Alfons J. Weichenrieder, On the Economics of Bottle Deposits, July 2004

1244 Sören Blomquist and Vidar Christiansen, Taxation and Heterogeneous Preferences, July 2004

1245 Rafael Lalive and Alois Stutzer, Approval of Equal Rights and Gender Differences in Well-Being, July 2004

1246 Paolo M. Panteghini, Wide vs. Narrow Tax Bases under Optimal Investment Timing, July 2004

1247 Marika Karanassou, Hector Sala, and Dennis J. Snower, Unemployment in the European Union: Institutions, Prices, and Growth, July 2004

1248 Engin Dalgic and Ngo Van Long, Corrupt Local Government as Resource Farmers: The Helping Hand and the Grabbing Hand, July 2004

1249 Francesco Giavazzi and Guido Tabellini, Economic and Political Liberalizations, July 2004

1250 Yin-Wong Cheung and Jude Yuen, An Output Perspective on a Northeast Asia Currency Union, August 2004

1251 Ralf Elsas, Frank Heinemann, and Marcel Tyrell, Multiple but Asymmetric Bank Financing: The Case of Relationship Lending, August 2004

1252 Steinar Holden, Wage Formation under Low Inflation, August 2004

1253 Ngo Van Long and Gerhard Sorger, Insecure Property Rights and Growth: The Roles of Appropriation Costs, Wealth Effects, and Heterogeneity, August 2004

1254 Klaus Wälde and Pia Weiß, International Competition, Slim Firms and Wage Inequality, August 2004

1255 Jeremy S. S. Edwards and Alfons J. Weichenrieder, How Weak is the Weakest-Link Principle? On the Measurement of Firm Owners’ Control Rights, August 2004

1256 Guido Tabellini, The Role of the State in Economic Development, August 2004

1257 François Larmande and Jean-Pierre Ponssard, EVA and the Controllability-congruence Trade-off: An Empirical Investigation, August 2004 
1258 Vesa Kanniainen and Jenni Pääkkönen, Anonymous Money, Moral Sentiments and Welfare, August 2004

1259 Panu Poutvaara and Andreas Wagener, Why is the Public Sector More Labor-Intensive? A Distortionary Tax Argument, August 2004

1260 Lars P. Feld and Stefan Voigt, Making Judges Independent - Some Proposals Regarding the Judiciary, August 2004

1261 Joop Hartog, Hans van Ophem, and Simona Maria Bajdechi, How Risky is Investment in Human Capital?, August 2004

1262 Thomas Eichner and Rüdiger Pethig, Efficient Nonanthropocentric Nature Protection, August 2004

1263 David-Jan Jansen and Jakob de Haan, Look Who's Talking: ECB Communication during the First Years of EMU, August 2004

1264 David F. Bradford, The X Tax in the World Economy, August 2004

1265 Hans-Werner Sinn, Migration, Social Standards and Replacement Incomes. How to Protect Low-income Workers in the Industrialized Countries against the Forces of Globalization and Market Integration, August 2004

1266 Wolfgang Leininger, Fending off one Means Fending off all: Evolutionary Stability in Submodular Games, August 2004

1267 Antoine Bommier and Bertrand Villeneuve, Risk Aversion and the Value of Risk to Life, September 2004

1268 Harrie A. A. Verbon and Lex Meijdam, Too Many Migrants, Too Few Services: A Model of Decision-making on Immigration and Integration with Cultural Distance, September 2004

1269 Thomas Eichner and Rüdiger Pethig, Economic Land Use, Ecosystem Services and Microfounded Species Dynamics, September 2004

1270 Federico Revelli, Performance Rating and Yardstick Competition in Social Service Provision, September 2004

1271 Gerhard O. Orosel and Klaus G. Zauner, Vertical Product Differentiation When Quality is Unobservable to Buyers, September 2004 